\title{
A Novel Approach for Optimizing the Supply Chain: A Heuristic-Based Hybrid Algorithm
}

\author{
Yasemin Kocaoglu $\mathbb{D}^{1},{ }^{1}$ Emre Cakmak $\mathbb{D},{ }^{2}$ Batuhan Kocaoglu $\mathbb{D}^{\mathbb{D}},{ }^{3}$ and Alev Taskin Gumus $\mathbb{I D}^{1}$ \\ ${ }^{1}$ Industrial Engineering, Yildiz Technical University, Istanbul 34349, Turkey \\ ${ }^{2}$ International Logistics and Transportation, Piri Reis University, Istanbul 34940, Turkey \\ ${ }^{3}$ Management Information Systems, Piri Reis University, Istanbul 34940, Turkey \\ Correspondence should be addressed to Yasemin Kocaoglu; coskunyasemin@gmail.com
}

Received 9 August 2019; Revised 13 January 2020; Accepted 14 January 2020; Published 27 February 2020

Academic Editor: Qiuye Sun

Copyright ( $\odot 2020$ Yasemin Kocaoglu et al. This is an open access article distributed under the Creative Commons Attribution License, which permits unrestricted use, distribution, and reproduction in any medium, provided the original work is properly cited.

\begin{abstract}
Managing the distribution of goods is a vital operation for many companies. A successful distribution system requires an effective distribution strategy selection and optimum route planning at the right time and minimum cost. Furthermore, customer's demand and location can vary from order to order. In this situation, a mixed delivery system is a good solution for it and allows the use of different strategies together to decrease delivery costs. Although the "distribution strategy selection" is a critical issue for companies, there are only a few studies that focus on the mixed delivery network problem. There is a need to propose an efficient solution for the mixed delivery problem to guide researchers and practitioners. This paper develops a new "modified" savings-based genetic algorithm which is named "distribution strategy selection and vehicle routing hybrid algorithm (DSSVRHA)." Our new algorithm aims to contribute to the literature a new hybrid solution to solve a mixed delivery network problem that includes three delivery modes: "direct shipment," "milk run," and "cross-docking" efficiently. It decides the appropriate distribution strategy and also optimal routes using a heterogeneous fleet of vehicles at minimum cost. The results of the hybrid algorithm are compared with the results of the optimization model. And the performance of the hybrid algorithm is validated with statistical analysis. The computational results reveal that our developed algorithm provides a good solution for reducing the supply chain distribution costs and computational time.
\end{abstract}

\section{Introduction}

Today's organizations are trying to find better distribution strategies that reduce supply chain costs and enhancing customer satisfaction to survive in the competitive supply chain environment. Therefore, delivery with the most costeffective distribution strategy has recently become a critical focus of logistics systems.

There are several types of distribution strategies: direct shipment, cross-docking, milk run, and mixed delivery. In direct shipment, all products are carried out from suppliers to customers or producers or directly to retailers. This strategy is economical if there is a full truck of shipment. Milk run reduces transportation costs by combining shipments from multiple locations with a single truck [1]. Milk run can be daily or weekly depending on the business model and the geographic location of the customers [2]. Small lot size and high frequency are characteristics of milk runs and are often used to deploy the just-in-time (JIT) strategy in logistical systems [3]. This strategy has been used in various industries. In a cross-docking strategy, the products are received and collected at a cross-docking center. And afterward, they are delivered to the customer destinations directly from a cross-docking center. Crossdocking is an appropriate distribution strategy in cases where each truck is fully or almost fully loaded. Crossdocking can reduce total inventory costs and lead time and improve customer service level and the relationships with 
suppliers [4]. A mixed delivery system allows implementing two or three distribution strategies together. A mixed distribution strategy is the best strategy in satisfying customer demand flexibility.

In recent years, vehicle routing problem along with selecting the right distribution strategy has become an important problem. Distribution locations and quantities vary from order to order. Selecting an appropriate vehicle route for distribution is extremely difficult. In the literature, there exists a wide variety of exact techniques and efficient heuristics for the vehicle routing problem. Earlier exact techniques include ones such as branch-and-bound algorithm [5, 6], branch and cut [7], and branch and price [8]. Exact techniques are simple, and their solutions are based on integer and mixed-integer programming. Dondo et al. [9] studied multiechelon distribution networks with the crossdocking strategy and presented a mixed-integer linear mathematical formulation. Hasani-Goodarzi and TavakkoliMoghaddam [10] proposed a mixed-integer linear programming (MILP) model for the vehicle routing problem, considering split deliveries, with the cross-docking strategy. Santos et al. [11] implemented an integer program (IP) and a branch-and-price-algorithm for solving the pickup and delivery problem with the cross-docking strategy. Agustina et al. [12] modeled a mixed-integer linear program for solving the vehicle scheduling and routing problem at a cross-docking center. Exact algorithms are efficient for solving small-scale vehicle routing problems. It is difficult to find a solution in a limited time frame with the exact algorithms for large-scale vehicle routing problems. That is what motivated the researchers to develop heuristic algorithms. Two earlier heuristics for vehicle routing problems are savings algorithm [13] and sweep algorithm [14]. These heuristics quickly produce feasible solutions. Xu et al. [15] studied a mixed delivery system that allows direct shipment, cross-docking, and milk run strategies. They developed a heuristic algorithm, based on Clark and Wright's algorithm, to determine the right distribution strategy and vehicle routes. This study proves that a mixed delivery system is more cost-effective than a pure delivery system. Dondo and Cerdá [16] proposed a sweep heuristic-based algorithm for the vehicle routing problem with the cross-docking strategy. They determined vehicle routes and schedules simultaneously at the cross-dock center. Mei et al. [17] developed an improved version of Clarke and Wright's algorithm for modeling vehicle routing problems with the milk run strategy. The study results show that the improved algorithm seeks to complete all goods distribution requirements efficiently.

Heuristics that developed recently are intelligent techniques, and they produce better solutions than the earlier heuristics or optimal solutions. These techniques are powerful especially when solving combinatorial optimization problems. Intelligent heuristic algorithms for vehicle routing problems commonly include genetic algorithm, simulated annealing algorithm, tabu search algorithm, and ant colony algorithm [18]. Lee et al. [19] proposed a heuristic algorithm based on a tabu search algorithm for vehicle routing scheduling with the cross-docking strategy. Wen et al. [20] studied vehicle routing problem with cross-docking and developed a tabu search heuristic that embedded within an adaptive memory procedure to solve the problem. Musa et al. [21] formulated an integer programming (IP) model for the distribution problem of cross-docking, and they solved it using an ant colony optimization (ACO) algorithm. Moghadam et al. [22] proposed a hybrid algorithm combining the ant colony algorithm and the simulated annealing algorithm to solve the vehicle routing scheduling problem with the cross-docking strategy. Mousavi and TavakkoliMoghaddam [23] developed a two-stage hybrid algorithm with simulated annealing and tabu search algorithms to solve location-routing scheduling problems with crossdocking. Hosseini et al. [24] presented a hybrid algorithm that combines the simulated annealing and the harmony search algorithm to find a solution for the vehicle routing problem with cross-docking and milk run strategies. Sadjadi et al. [25] solved milk run problem by using the genetic algorithm (GA), and the results indicate that the proposed method significantly reduces the cost of logistics. Baniamerian et al. [26] introduced three echelon supply chain problems with cross-docking and proposed a two-phase genetic algorithm (GA) focusing on customer satisfaction. Baniamerian et al. [27] studied a heterogeneous vehicle routing problem with cross-docking and developed a hybrid genetic algorithm with modified variable neighborhood search. When the results were compared with the simulated annealing (SA) algorithm and artificial bee colony (ABC) algorithm, the proposed hybrid algorithm had given significantly better results than the others.

The main contributions are summarized as follows:

(1) In a competitive supply chain environment, a mixed delivery system is the best solution that allows using different distribution strategy combinations in reducing logistics costs. As we can see from the literature review, the mixed delivery system has not been emphasized enough. There is a need to propose an efficient solution for the mixed delivery problem to guide researchers and practitioners. This paper focuses on a mixed delivery system network problem that allows three delivery modes: cross-docking, milk run, and direct shipment. A hybrid algorithm is proposed combining the genetic algorithm and Clarke and Wright's algorithm to solve this mixed delivery network problem. This algorithm aims to contribute to the literature a new hybrid solution to solve the mixed delivery system problem efficiently. The new algorithm decides on an appropriate distribution strategy and optimum vehicle routes while significantly reducing logistics costs.

(2) To the best of our knowledge, this is the first time the genetic algorithm has been hybridized with Clarke and Wright's algorithm for the heterogeneous vehicle routing problem with mixed delivery strategies. The study of Clarke and Wright [13] satisfies all distribution requirements efficiently with minimal vehicles, the shortest mileage, and the lowest cost. The following papers are proof of this: [15, 17]. 
Clarke and Wright's algorithm provides good solutions for small-size instances. For large-size instances, developing a hybrid algorithm provides better results. The genetic algorithm is an intelligent heuristic technique for solving vehicle routing problems by reducing delivery costs significantly, and the following papers prove this: [25-27]. Thus, this paper chooses two well known and proven algorithms to solve the mixed delivery problem efficiently.

(3) Today, many businesses see the use of 3PL (thirdparty logistics) provider as an option to reduce costs and improve customer service. The authors of References [21, 28] employed this approach in their paper with a homogeneous and unlimited number of vehicles. In this paper, the 3PL (third-party logistics) provider in a mixed distribution system with heterogeneous and unlimited number of vehicles are employed as a different approach.

Figure 1 shows the flow of the paper. The paper starts with an introduction and proceeds with the literature review. Section 3 defines optimization model of the problem. Section 4 presents the proposed hybrid algorithm. Section 5 shows a case study of the proposed algorithm. The last section presents the conclusions and gives a brief regarding the direction of future research.

\section{Literature Review}

A supply chain is an integrated system that includes a variety of distribution actors such as facilities, suppliers, manufacturers, and distributors. In supply chain management, multiple organizations participate in a collaborative task via a business process [29]. Supply chain design with energy and sustainability issues is a popular research topic [30]. Zhao et al. [31] focused on developing minimization of risks in green logistics based on a multiobjective optimization model. Wang et al. [32] emphasized application of the technology equipment's for the optimization of renewable energy resources. Zhang et al. [33] stated that energy management problems can be formulated as an optimization problem. Li et al. [34] emphasized the importance of energy problem whose major purpose is to maximize the resource allocation profits or minimize the energy costs while meeting the coupled matrix constraint and a set of system operation constraints. This type of optimization problems arises in a broad range of applications including energy management and electric vehicle aggregator [35]. Apte and Viswanathan [36] stated that $30 \%$ of the supply chain costs occurred during the distribution process [19]. At this point, an efficient distribution strategy selection and optimum vehicle route planning are necessities. A vehicle routing problem (VRP) is a well-known important combinatorial optimization problem in distribution management [37]. Efficient methods and optimization algorithms should be developed to solve this problem. Optimization models and methods for supply chain design are of great interest among industry and academic researchers [30]. There are many review papers

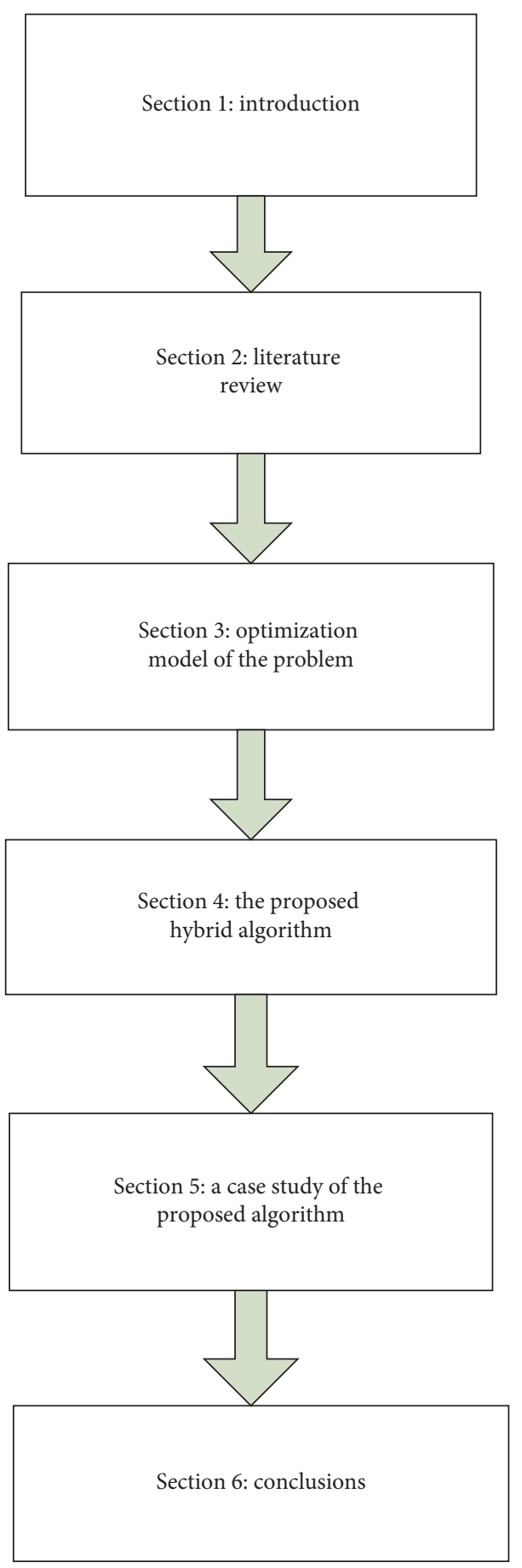

Figure 1: The flow of the paper.

about the optimization methods for vehicle routing problems, see the following papers for more information: [38-42]. The scope of our literature review is limited to the following distribution strategies for vehicle routing problems: cross-docking, milk run, and mixed delivery.

There has been extensive research on the vehicle routing problem (VRP) with cross-docking strategy. The crossdocking is an efficient strategy that reduces inventory, transportation, and holding costs. It requires lower stock levels and less storage space. Lee et al. [19] developed a 
mathematical model and a heuristic method, based on the tabu search algorithm, for both cross-docking and vehicle routing with time windows. They randomly generated problems and found optimal solutions that were close to optimal with a $4 \%$ error within a reasonable time.

Wen et al. [20] addressed the vehicle routing with crossdocking, where the data of homogeneous vehicles are used. They formulated a mixed-integer programming model considering time window constraints. And they implemented a tabu search heuristic method that embedded within an adaptive memory procedure. They tested the heuristic method on datasets provided by Danish consultancy Transvision. The results show that the heuristic method can give high-quality solutions within a short time.

Liao et al. [43] implemented a model that integrates cross-docking into the vehicle routing problem using a set of homogeneous, capacity, and number limited vehicles. In their paper, they developed a new tabu search heuristic method, and they proved that the new algorithm performs better than a tabu search algorithm.

Hasani-Goodarzi and Tavakkoli-Moghaddam [10] examined the capacity-limited vehicle routing problem for multiproduct cross-docking with allowing split deliveries, and the problem is formulated as a mixed-integer linear programming (MILP) model for small-sized problems.

Mousavi and Tavakkoli-Moghaddam [23] suggested a two-stage hybrid algorithm (HSA), which is the combination of simulated annealing, and a tabu search algorithm, for location-routing scheduling problems with cross-docking. Santos et al. [11] proposed a branch-and-price algorithm and linear programming branch-and-bound (LPBB) method for a cross-docking problem considering homogeneous, number, and capacity-limited vehicles.

Mousavi et al. [44] offered a hybrid fuzzy possibilisticstochastic programming solution for the location-routing problem of cross-docking centers.

Agustina et al. [12] studied the vehicle routing problem with cross-docking for food delivery considering just-intime strategy. They modeled the problem as a mixed-integer linear program with a time window.

Baniamerian et al. [26] solved the cross-docking vehicle routing and scheduling problem focusing on improving customer satisfaction and time windows by developing a mixed-integer programming (MIP) model and a two-phase genetic algorithm.

Wang et al. [45] presented a new vehicle routing problem with cross-docking, considering split deliveries and heterogeneous and capacity-limited vehicles. They established a mixed-integer linear programming model and proposed a solution method combining a constructive heuristic approach and two-layer simulated annealing and tabu search. Their experimental results show that the proposed method solves large-size problems effectively within a reasonable time.

Ahkamiraad and Wang [46] studied a distribution problem with multiple cross-docks, where a set of homogeneous, number, and capacity-limited vehicles with time window was considered. They modeled the problem as mixed-integer linear programming and proposed a hybrid of the genetic algorithm and particle swarm optimization. It has been proven that the proposed hybrid algorithm provides better solutions than the exact method for small-size problems.

Milk run, which is another efficient distribution strategy, has been successfully applied to the logistics activities of various industries. The milk run strategy has the advantages of reducing distances and logistics costs by providing a high delivery frequency. Milk run routing problems with homogeneous, capacitated, and limited vehicle fleets were studied in the following papers: [17, 25]. Sadjadi et al. [25] implemented a mixed-integer programming model and the genetic algorithm (GA) considering homogeneous-, number-, and capacity-limited vehicles to solve the milk run problem of the auto industry. The GA results indicate that the use of GA can produce a near-optimal solution and significantly reduce lower supply chain costs. You and Jiao et al. [47] presented the milk run distribution problem of the express company. They improved the traditional Clarke and Wright's algorithm and then tested the algorithm with 10 distribution nodes. They stated that the algorithm could effectively reduce the distance and costs with reasonable route planning. Mei et al. [17] proposed an improved version of Clarke and Wright's algorithm for a milk run vehicle routing problem of the Anji logistics company considering time window. The results show that the improved approach reduces logistics costs and it could provide reduced these costs for other companies in the business also.

In real life, suppliers and customers are located randomly, and delivery quantities vary from order to order. In this case, a mixed delivery system can be a better distribution option than a pure delivery system. However, a mixed distribution system has received less attention in the literature [15]. Xu et al. [15] studied a mixed delivery system with both hub-and-spoke and direct shipment. They developed a heuristic approach based on Clarke and Wright's algorithm. Their experiments indicate that the mixed system is more effective than using a pure system. They provided researchers with a direction, to have better solutions, for trying different methods like a genetic algorithm and/or tabu search. Berman and Wang [48] proposed a Greedy heuristic, a Lagrangian relaxation heuristic, and a branch-and-bound algorithm to select the appropriate distribution strategy (decision of cross-docking or direct shipment) and vehicle routes for inbound logistics planning. Branke et al. [49] developed an evolutionary algorithm (EA) by combining savings heuristic to solve transport channel selection and vehicle routing problem simultaneously. They proved that their hybrid algorithm could significantly reduce the transportation cost better than simple heuristics. Musa et al. [21] studied the distribution planning problem that determines the loads to be delivered by direct shipment or crossdocking from the supplier to customers. In this study, the distribution is carried out with third-party logistics (3PL) providers, where the vehicles are ready for use when necessary. They proposed a novel ant colony optimization (ACO) algorithm to solve this problem. The results showed that the proposed algorithm provides better solutions than branch-and-bound (B\&B) solutions. Dondo et al. [9] studied 
the vehicle routing problem (VRP) with hybrid strategies combining direct shipping, warehousing, and cross-docking. They presented a mixed-integer linear programming model where the following constraints are taken into account: heterogeneous vehicle, vehicle capacity limitation, travel distance limitation, and time window. Charkhgard and Yahya Tabar [28] extended the paper [21], which focused on distribution planning with the decisions of direct shipment or cross-docking by implementing third-party logistics providers. In this paper, a mixed-integer nonlinear programming (MINLP) model is formulated, and a simulated annealing (SA) heuristic algorithm is applied. Hosseini et al. [24] offered an integer programming model and a hybrid heuristic method based on harmony search (HS) and simulated annealing (SA) for the transportation problem which consists of direct shipment, cross-docking, and milk run. They pointed out that the hybrid approach has better performance in reducing computational and transportation costs for large-size instances. Cóccola et al. [50] solved a real vehicle routing problem with developing a branch-and-price solution-algorithm to determine which of the two different delivery options (direct delivery or cross-docking) would be used. Goodarzi and Zegordi [51] proposed a metaheuristic algorithm named biogeography-based optimization (BBO) for the location-routing problem of cross-docking. The algorithm determines cross-docking locations and vehicle routing with selecting one of the transportation strategies (direct shipment or shipment through cross-dock). Meyer and Amberg [52] developed a mixed-integer linear programming model addressing the transport concept selection problem of automotive manufacturers, which includes milk run, area forwarding, and point-to-point transport. Their study showed how to establish a mixed distribution network.

Figure 2 presents a brief review of our literature review. The "distribution characteristics" column indicates the papers that have the following vehicle routing constraints: time window, travel time limitation, travel distance limitation, vehicle capacity limitation, homogeneous/heterogeneous vehicle, limited/unlimited number of vehicles, and split deliveries. The "distribution strategies" column presents the papers that have the following distribution strategies: crossdocking/area Forwarding/hub-and-spoke, direct shipment milk run, and groupage service. "The use of the genetic algorithm and Clarke Wright algorithm" column presents the papers that employ the genetic algorithm and Clarke and Wright algorithm. The "solution method" column presents the exact/heuristic/metaheuristic method of the papers. The "distribution strategy selection" column presents the papers that are interested in distribution strategy selection.

As illustrated in Figure 2, a mixed distribution system, which consists of cross-docking, direct shipment, and milk run, has not been emphasized enough in the literature. In real life, suppliers and customers are located randomly, and delivery quantities vary from order to order. Although the hybrid distribution system has received less attention in the literature, a mixed distribution system may be a better distribution option than practicing a single distribution option [15]. So, there is a need to propose an efficient solution for the mixed delivery problem to guide researchers and practitioners. This paper proposes a hybrid algorithm to solve a mixed delivery network problem. The algorithm determines the best distribution strategy and optimum vehicle routes while significantly reducing costs.

To the best of our knowledge, this is the first time the genetic algorithm has been hybridized with Clarke and Wright's algorithm for the heterogeneous vehicle routing problem with mixed delivery strategies, which consists of cross-docking, milk run, and direct shipment. Clarke and Wright's algorithm is one of the popular and simple algorithms that reduce travel distance and logistics costs efficiently with minimal vehicle requirements. As we mentioned above, $\mathrm{Xu}$ et al. [15] proposed a heuristic method based on Clarke and Wright's algorithm for a mixed delivery system. Their studies indicate that the use of Clarke and Wright's algorithm, with reasonable route planning, reduced the distance and costs for small-size instances. They gave a direction for researchers to try different methods like a genetic algorithm or tabu search, to reach better results. The genetic algorithm is a well-known and powerful algorithm to solve different vehicle routing problems, reducing delivery costs significantly by producing better solutions. The following papers are proof of this: [25-27, 46]. And Branke et al. [49] showed that the hybrid algorithm could better reduce logistics costs than simple heuristics by developing an evolutionary algorithm (EA), combining savings heuristic for transport channel selection and vehicle routing problem. In this paper, inspired by the studies mentioned above, and for having better results, we hybridized two well-known and proven algorithms (genetic algorithm and Clarke and Wright's algorithm) to solve a mixed delivery network problem with heterogeneous vehicles efficiently.

A simple way to increase the efficiency of the supply chain is to outsource third-party logistics (3PL) companies that operate at high-efficiency levels [50]. The authors of References $[21,28]$ implemented this approach in their paper by homogeneous and an unlimited number of vehicles. In this paper, we implemented a 3PL (third-party logistics) provider in a mixed distribution system by employing a heterogeneous and an unlimited number of vehicles as a different approach.

Table 1 presents the abbreviations of the solution methods which are shown in Figure 2.

\section{Optimization Model of the Problem}

We, considering the literature discussed in the previous section, studied a two-stage distribution network problem. In this scenario, finished goods are distributed to customers/ retailers from manufacturer/supplier with three available distribution methods: "direct shipment," "cross-docking," and "milk run" (Figure 3). The distribution network in this paper consists of a manufacturer/supplier, a cross-docking center, and customers. This type of distribution network is common for the automotive industry, food industry, and electronic manufacturing industry. In this paper, the mixed delivery network problem is studied to offer an efficient distribution solution to minimize the total distribution costs. 


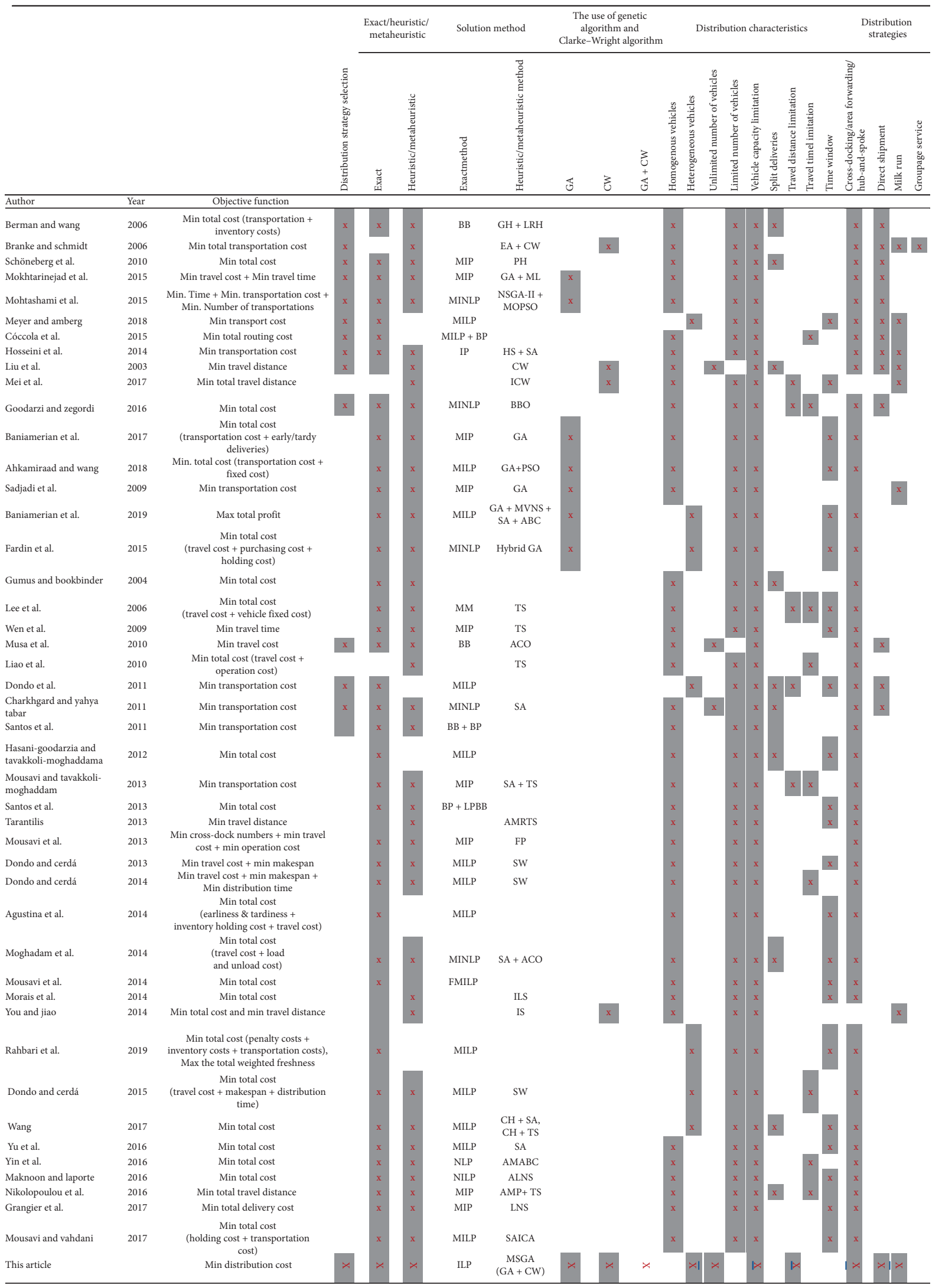

FIGURE 2: The brief review of the literature review. 
TABLE 1: Abbreviation table.

\begin{tabular}{|c|c|}
\hline Abbreviation & Description \\
\hline FMILP & Fuzzy mixed-integer linear programming \\
\hline NLP & Nonlinear programming \\
\hline NILP & Noninteger linear programming \\
\hline ILP & Integer linear programming \\
\hline IP & Integer programming \\
\hline MIP & Mixed-integer programming \\
\hline MILP & Mixed-integer linear programming \\
\hline MINLP & Mixed-integer nonlinear programming \\
\hline $\mathrm{B} \& \mathrm{~B}$ & Branch-and-bound algorithm \\
\hline $\mathrm{GH}$ & Greedy heuristic \\
\hline LRH & Lagrangian relaxation heuristic \\
\hline $\mathrm{ACO}$ & Ant colony optimization \\
\hline SA & Simulated annealing \\
\hline TS & Tabu search \\
\hline HS & Harmony search \\
\hline ALNS & Adaptive large neighborhood search \\
\hline AMP & Adaptive memory programming \\
\hline AMABC & Adaptive memory artificial bee colony \\
\hline PSO & Particle swarm optimization \\
\hline GA & Genetic algorithm \\
\hline NSGA-II & Nondominated sorting genetic algorithm \\
\hline MOPSO & Multiobjective particle swarm optimization \\
\hline ML & Machine learning \\
\hline $\mathrm{BP}$ & Branch and price \\
\hline LPBB & Linear programming-based branch and bound \\
\hline $\mathrm{BBO}$ & Biogeography-based optimization \\
\hline AMRTS & Adaptive multirestart tabu search \\
\hline $\mathrm{PH}$ & Primal heuristics \\
\hline $\mathrm{CW}$ & Clarke and Wright's algorithm \\
\hline CG & Column generation \\
\hline EA & Evolutionary algorithm \\
\hline FP & Fuzzy programming \\
\hline SW & Sweep algorithm \\
\hline ILS & Iterated local search \\
\hline MSGA & Modified savings-based genetic algorithm \\
\hline IS & Improved saving \\
\hline ICW & Improved Clarke and Wright's algorithm \\
\hline $\mathrm{ABC}$ & Artificial bee colony \\
\hline MVNS & Modified variable neighborhood search \\
\hline SAICA & Self-adaptive imperialist competitive algorithm \\
\hline $\mathrm{CH}$ & Constructive heuristic approach \\
\hline
\end{tabular}

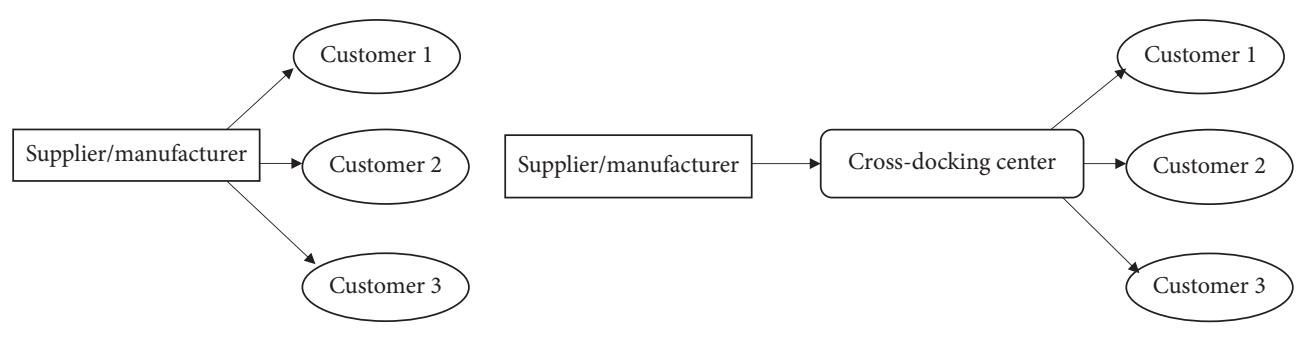

(a)

(b)

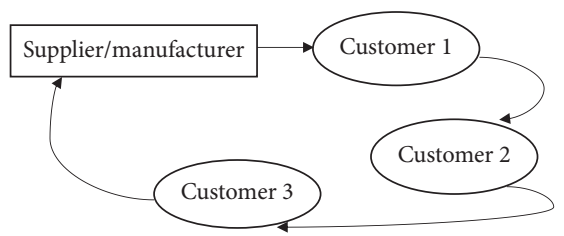

(c)

Figure 3: Distribution strategies. (a) Direct shipment. (b) Cross-docking. (c) Milk run. 
We developed a new mathematical model, shown below, with the help of the models developed by Laporte [41] and Hosseini et al. [24]. The mathematical model determines the proper distribution strategy and optimal routes.

The mathematical model makes the following assumptions:

(1) Customer orders are not split, so only one vehicle can be assigned to each customer.

(2) The vehicle fleet is heterogeneous, and all vehicles have a different capacity.

(3) There are no limits to the number of vehicles, assuming that each type of vehicle is ready for use when needed (this is only possible with the use of a third-party logistics (3PL) provider).

(4) In milk run, the stop costs are incurred when the vehicles stop at each customer.

(5) Customer orders are not delayed and are satisfied daily. Therefore, penalty costs are not incurred.

(6) The milk run route length of the vehicle is bounded by a given distance due to the driver's legal driving times.

(7) Customer demand quantities are deterministic and known.

(8) The total load shipped by each vehicle cannot exceed the vehicle capacity.

(9) The manufacturer/supplier capacity is sufficient to meet the demand of all customers.

(10) There is one cross-docking center, and there is no stock in the cross-docking center.

(11) The cross-docking transportation from the manufacturer/supplier to the cross-docking center is made by truck. The shipments are distributed from the cross-dock to the customers directly with smaller trucks, and this direct shipment cost is priced according to customer's demand volume.

The parameters and the definitions used in the model are as follows:

(i) Indices

$N_{0}=$ set of nodes with manufacturer/supplier $\{i$, $j=0,1,2,3, \ldots, n\}$

$N=$ set of customer nodes $\{i, j=1,2,3, \ldots, n\}$

$V=$ set of vehicles $\{V=1,2,3,4, \ldots, v\}$.

$K=$ cross-docking center

(ii) Parameters

$K_{\mathrm{v}}$ : the maximum loading capacity of the vehicles $\left(\mathrm{m}^{3}\right)\{v=1,2,3,4, \ldots, v\}$.

$d_{j}$ : the volume of customer $j$ shipments $\left(\mathrm{m}^{3}\right), j \varepsilon N$

$C_{i j}$ : total distance between customer $i$ and customer $j(\mathrm{~km})$

$S$ : truck capacity for cross-docking center

$D$ : milk run tour length $(\mathrm{km})$

$L v$ : rental cost of vehicle $\{v=1,2,3,4, \ldots, v\}$
$O$ : fixed cost of transportation from the manufacturer/supplier to a cross-docking center $W$ : milk run stop cost (milk run stop cost arises when the vehicle delivers a product to the customers. It is considered as the cost of the time it takes to deliver the product to the customer) $T$ : direct shipment cost from the cross-docking center to customers.

$P$ : cost per unit of gasoline consumed per $\mathrm{km}$

(iii) Decision variables

$X_{i j v}=\left\{\begin{array}{l}1 \\ 0\end{array}\right.$ if vehicle $v$ travels from customer $i$ to customer $j 1$, otherwise 0 ; $i \varepsilon$ No, $j \varepsilon$ No ve $i \neq j, v$

$\begin{aligned} & \varepsilon V \\ & Z_{j v}\end{aligned}=\left\{\begin{array}{l}1 \\ 0\end{array}\right.$ if vehicle $v$ travels directly to customer

$j 1$, otherwise $0 ; j \varepsilon N$ ve $v \varepsilon V$

$Y_{j}=\left\{\begin{array}{l}1 \\ 0\end{array}\right.$ if customer $j$

demand is transported with cross -

docking 1, otherwise $0 ; j \varepsilon N$

$M=$ number of trucks used for shipment from the manufacturer/supplier to the cross-docking center

(iv) Objective value

Min $Z=$ direct shipment cost + milk run cost+ cross-docking cost

Direct shipment cost $=$ Total rental cost of vehicles + total gasoline consumption of direct shipment $=$ $\sum_{i=0, j \varepsilon N} \sum_{v \varepsilon V} Z_{j v} \cdot\left(L_{v}+C_{i j} \cdot P_{v}\right)$

Milk run cost $=$ total rental cost of vehicles + total gasoline consumption of milk run route + total milk run stop cost $=\sum_{i=0, j \varepsilon N} \sum_{v \varepsilon V} X_{i j v} \cdot\left(L_{v}+\right.$ $\left.C_{i j} \cdot P_{v}\right)+\sum_{i \varepsilon N} \sum_{j \varepsilon N} \sum_{v \varepsilon V} X_{i j v} \cdot C_{i j} \cdot P_{v}+\sum_{i \varepsilon N 0} \sum_{j \varepsilon N} \sum_{v \varepsilon V}$
$W \cdot X_{i j v}$

Cross-docking cost $=$ total cost for shipment from the manufacturer/supplier to the cross-docking center + direct shipment cost from the crossdocking center to customers $=M \cdot O+\sum_{j \varepsilon N} T \cdot Y_{j}$

The model formulation is as follows:

$$
\begin{aligned}
\operatorname{Min} Z= & \sum_{i=0, j \varepsilon N} \sum_{v \varepsilon V} Z_{j v} \cdot\left(L_{v}+C_{i j} \cdot P_{v}\right) \\
& +\sum_{i=0, j \varepsilon N} \sum_{v \varepsilon V} X_{i j v} \cdot\left(L_{v}+C_{i j} \cdot P_{v}\right) \\
& +\sum_{i \varepsilon N} \sum_{j \varepsilon N} \sum_{v \varepsilon V} X_{i j v} \cdot C_{i j} \cdot P_{v}+\sum_{i \varepsilon N 0} \sum_{j \varepsilon N} \sum_{v \varepsilon V} W \cdot X_{i j v} \\
& +M \cdot O+\sum_{j \varepsilon N} T \cdot Y_{j}, \\
& \sum_{i \varepsilon N o} \sum_{v \varepsilon V} X_{i j v}+\sum_{v \varepsilon V} Z_{j v}+y_{j}=1, \quad \forall j \varepsilon N, i \neq j,
\end{aligned}
$$




$$
\sum_{i \varepsilon \text { No }} \sum_{j \varepsilon N} d_{j} \cdot X_{i j v} \leq K_{v}, \quad \forall v \varepsilon V, V=1,2,3,4, \ldots, v, i \neq j
$$

$$
\sum_{i \varepsilon S} \sum_{j \varepsilon S \backslash\{i\}} X_{i j v}|S|-1, \quad \forall S \subset N,|S| \geq 2, V=1,2,3,4, \ldots, v,
$$

$$
\sum_{v \varepsilon V} X_{i j v}+\sum_{v \varepsilon V} Z_{i v}+Y_{i} \leq 1, \quad \forall i \varepsilon N, j=0
$$

$\sum_{v \varepsilon V} X_{j i v}+\sum_{v \varepsilon V} Z_{i v}+Y_{i} \leq 1, \quad \forall i \varepsilon N, j=0$

$\sum_{j \varepsilon N} X_{j i v}+\sum_{j \varepsilon N} Z_{j v} \leq 1, \quad \forall v \varepsilon V, i=0, j \neq 0, i \neq j$

$\sum_{i \varepsilon \mathrm{No}} X_{i j v}-\sum_{l \varepsilon \mathrm{No}} X_{j l v}=0, \quad \forall j \varepsilon N, \forall, v \varepsilon V, i \neq j, 1 \neq j$

$d_{i} \cdot \sum_{i \varepsilon N} Z_{i v} \leq K_{v}, \quad \forall i \varepsilon N, \forall v \varepsilon V, V=1,2,3,4, \ldots, v$

$\sum_{j \varepsilon N} d_{j} \cdot Y_{j} \leq \mathrm{M} \cdot \mathrm{S}, \quad s \varepsilon S$

$\sum_{i \varepsilon N o} \sum_{j \varepsilon N o} C_{i j} \cdot X_{i j v} \leq D, \quad \forall v \varepsilon V, i \neq j$

$$
\begin{aligned}
& \sum_{j \varepsilon N} Y_{j} \leq N, \\
& X_{i j v} \varepsilon\{0,1\}, \\
& Z_{i v} \varepsilon\{0,1\}, \\
& Y_{i v} \varepsilon\{0,1\} .
\end{aligned}
$$

Formula (1) is the objective function and aims to minimize the total distribution costs. Constraint (2) ensures that customer demands are met via one of the three available distribution strategies. Constraint (3) ensures that the sum of the amounts carried in the milk run tour does not exceed the vehicle capacity. Constraint (4) eliminates subtours. Constraints (5) and (6) guarantee that only one of the direct, crossdocking, or milk run distribution strategies will be available. Constraint (7) restricts the same vehicle from making both direct shipment and milk run tour. Constraint (8) guarantees that the same vehicle completes the milk run tour. Constraint (9) provides the assignment of the appropriate vehicle to meet the demands of the customer by direct shipment. Constraint (10) guarantees that the total amount shipped to the crossdocking center will meet customer demands. Constraint (11) restricts milk run route length. Constraint (12) guarantees that the assignment to the cross-docking center can be as much as the maximum number of customers. Constraints (13)-(15) provide that the variables take binary values of 0 or 1 .

\section{Proposed Hybrid Algorithm}

The vehicle routing problem is one of the more widely studied problems in combinatorial optimization. It comprises the traveling salesman problem (TSP) which includes a Hamiltonian cycle. Held and Karp [53] had shown that the TSP is an NP-hard (nondeterministic polynomial-time hard) problem as is the Hamilton path [54]. Because of this, the proposed mathematical model cannot solve large-size vehicle routing problems in a reasonable time.

We can see from the literature that the "genetic algorithm" has been used successfully to solve problems which integrate VRP and cross-docking [27, 44, 55]. On the contrary, the "Clarke and Wright" algorithm has been used successfully for solving the vehicle routing problem (VRP) $[15,17]$. Therefore, we propose a novel hybrid algorithm named "distribution strategy selection and vehicle routing hybrid algorithm" (DSSVRHA) combining Clarke and Wright's algorithm and genetic algorithm. This algorithm contributes to the literature a new hybrid solution to solve a mixed delivery network problem efficiently.

Our hybrid algorithm selects the optimal distribution strategy and determines optimal routes for milk run to provide the minimum total distribution costs. It consists of two subalgorithms: genetic and modified savings. The algorithm starts with GA. First, the genetic algorithm assigns distribution strategies to customers randomly. The modified savings algorithm creates the milk run route and selects the proper vehicle type and also calculates the distribution costs. The hybrid algorithm is explained in the following sections.

Step 1. GA-generate random population

(i) Initialization of the population: DeJong [56] and Grefenstette [57] proposed a population size of 100 . The population size of the papers in the literature varies from 20 to 100 [58]. In this paper, population size is determined as 100 according to these papers.

(ii) Assigning distribution strategies to customers randomly: the value coding approach is used in chromosome representation. The chromosome representation indicates which distribution strategy is assigned to customers: (1) cross-docking; (2) direct shipment; (3) milk run. The length of the chromosome is determined by the total number of customers. Distribution strategies are randomly assigned to customers. Figure 4 represents a sample chromosome for ten customers.

Step 2. Apply modified savings algorithm if method is equal to milk run

Clark and Wright [13] proposed a simple method for optimal routing of a fleet of vehicles, which have varying capacities, used for delivery from a depot to delivery points. The traditional savings method has three basic steps before starting route creation: (i) calculate savings between customers $i$ and $j$ with the [13] formula $S_{i j}=d_{i 0}+\mathrm{d}_{0 j}-\mathrm{d}_{i j}$ (the formulation is shown as below where $\mathrm{d}_{i j}$ denotes travel 


\begin{tabular}{|c|c|c|c|c|c|c|c|c|c|}
\hline 3 & 3 & 3 & 3 & 3 & 3 & 1 & 1 & 1 & 2 \\
\hline 1 & 2 & 3 & 4 & 5 & 6 & 7 & 8 & 9 & 10
\end{tabular}

FIgURE 4: A sample chromosome representation.

distance from customer $i$ to $j$ and " 0 " stands for the depot), (ii) sort savings in the descending order (iii) select customers $i$ and $j$ with the largest savings value. The developed modified procedure starts with traditional savings method Steps (i) and (ii), but it differentiates in Step (iii). Instead of selecting customers that have the maximum savings, the random selection procedure is applied when creating the routes. Thus, it is possible to create different milk run routes by avoiding local solutions. In the traditional savings method, there is possibly one customer on the route, but our modified procedure does not allow for only one customer on the route. When there is one customer on the route, the customer is served by the direct shipment strategy. The flowchart of the proposed modified savings algorithm is given in Figure 5.

The pseudocode of the modified savings is given below:

(1) [Traditional savings heuristic] Calculate savings for each customer pair $i-j$ that are assigned to the milk run in the chromosome.

(2) [Traditional savings heuristic] Rank $S_{i j}$ values in the descending order.

(3) [Modified savings heuristic] If unserved customers $>1$,

(a) Generate random numbers in the range $[0,1]$ and go to Step 4.

(b) If there is only one customer in the route,

(i) Serve customers by direct shipment, and calculate the milk run cost and end procedure.

(ii) Else calculate the milk run cost and end procedure.

(4) [Modified savings heuristic] If generated random number is $>0.9$ ( 0.9 is defined as the threshold value)

(a) Select customers $i$ and $j$ that are in the first rank in the savings list.

(b) Else select customers $i$ and $j$ that are in the next saving in the savings list.

(5) [Traditional savings heuristic] If customers $i$ and $j$ are the members of the route,

(a) Check if customers $i$ and $j$ are on the same route,

(i) Remove saving of customers $i$ and $j$ from the savings list and go to Step 3 .

(ii) Else check if customer $i$ or $j$ is the first or last customer on one of the routes.

(iii) Check if total demand of routes $<$ vehicle capacity?, go to iv, else go to Step 3.

(iv) Check if total travel distance $<$ the milk run tour length, merge the milk run routes, else go to Step 3. (b) Else check if total demand of customers $i$ and $j<$ vehicle capacity? go to step c, else go to Step 3 .

(c) Check if total travel distance $<$ the milk run tour length? create new route, else go to Step 3.

The modified savings procedure is explained with the chromosome indicated in Figure 4. The modified savings algorithm is applied for the customers that are randomly assigned to the milk run strategy in the chromosome, as shown below.

The objective is to identify and create milk run routes by minimizing the total distance. Because of the driver's legal driving time limit, the total travel distance is limited to 900 kilometer to satisfy customer demands daily. The distance matrix, demands of customers, and vehicle characteristics are presented in Tables 2-4. Savings calculation and modified savings results are shown in Tables 5 and 6.

Routes created by a modified savings algorithm are shown in Figure 6. Customer 3 is not on one of the milk run routes because when this customer is added into the routes, it causes a violation in vehicle capacity and travel distance. In the modified savings algorithm, when there is single customer in the route, the milk run route is canceled, and the customer is served by direct shipment.

Table 7 presents the traditional savings results, and Figure 7 shows routes that can be created by traditional savings. Table 8 indicates the improvement obtained by the modified savings algorithm. When we compare traditional savings results and modified savings results, we can see that our modified savings algorithm decreases the total distance by creating different routes based on random creation procedure.

After creating the milk run routes with the modified savings algorithm, the chromosome is repaired as indicated in Figure 8. Figures 8 and 9 indicate the chromosome representation before and after applying the modified savings algorithm ((1) cross-docking; (2) direct shipment; (3) milk run).

Step 3. Apply direct procedure if method is equal to direct shipment

(i) Assign proper vehicle type: for the customers assigned to a direct shipment strategy in the chromosome solution, the proper vehicle type is assigned according to customer demands. Figure 10 shows the customers are served by direct shipment.

(ii) Calculate direct shipment cost: direct shipment cost is calculated. It involves the fixed cost of the vehicle type and travel distance costs.

Step 4. Apply cross-docking procedure if method is equal to cross-docking 


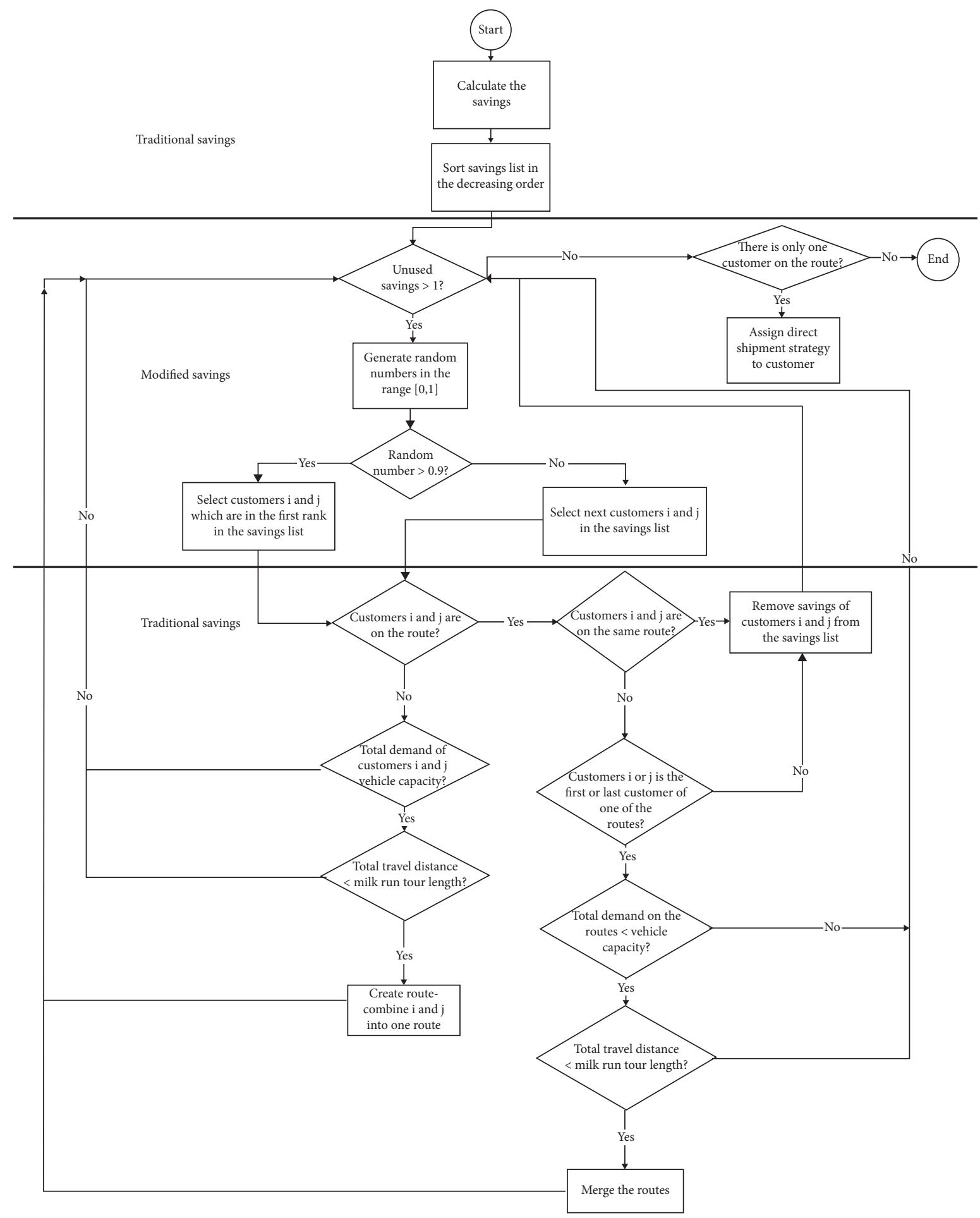

FIGURE 5: The flow of the modified savings algorithm.

(i) Consolidate customer demands to be shipped to cross-docking center: for the customers assigned to a cross-docking strategy in the chromosome solution, the total volume of demands is calculated. It is assumed that a sufficient number of trucks are used for shipment to cross-docking center. Figure 11 shows the customers that are served by cross-docking. (ii) Calculate cross-docking cost: this cost involves shipment cost to cross-docking center and direct shipment cost from the cross-docking center to the customer. Direct shipment cost from the crossdocking center to the customer is a fixed cost, varying according to the volume of customer demands. 
TABle 2: Distance matrix $(\mathrm{km})$.

\begin{tabular}{cccccccc}
\hline$d_{i j}$ & 0 & 1 & 2 & 3 & 4 & 5 & 6 \\
\hline 0 & 0 & 420 & 200 & 175 & 230 & 155 & 300 \\
1 & 420 & 0 & 175 & 330 & 300 & 165 & 180 \\
2 & 200 & 175 & 0 & 305 & 403 & 185 & 190 \\
3 & 175 & 330 & 305 & 0 & 280 & 149 & 300 \\
4 & 230 & 300 & 403 & 280 & 0 & 55 & 100 \\
5 & 155 & 165 & 185 & 149 & 55 & 0 & 45 \\
6 & 300 & 180 & 190 & 300 & 100 & 45 & 0 \\
\hline
\end{tabular}

TABLe 3: Demand $\left(\mathrm{m}^{3}\right)$.

\begin{tabular}{lc}
\hline Customers & Demand $\left(\mathrm{m}^{3}\right)$ \\
\hline 1 & 10 \\
2 & 20 \\
3 & 23 \\
4 & 5 \\
5 & 10 \\
6 & 30 \\
\hline
\end{tabular}

TABLE 4: Vehicle characteristics.

\begin{tabular}{lcc}
\hline Vehicle type & Capacity $\left(\mathrm{m}^{3}\right)$ & Vehicle cost $(\$)$ \\
\hline 1 & 9 & 86 \\
2 & 25 & 123 \\
3 & 30 & 137 \\
4 & 50 & 172 \\
\hline
\end{tabular}

Step 5. GA-evaluate the fitness value

The fitness value is the distribution cost of solutions, and it is calculated according to (1) (Section 3). Distribution cost involves direct shipment cost, cross-docking cost, and milk run cost. The costs are ranked in the descending order since it is a minimization problem. The lowest cost is kept as the optimum cost.

Step 6. GA-create new population

(i) Selection: the selection process is applied in GA to select parent chromosomes based on their fitness function value. The roulette-wheel selection procedure proposed by Goldenberg [59] is used for selecting chromosomes in the selection process. The selection probability is calculated by $p_{i}=f_{i} \sum_{i}^{N} f_{i}$ where $f_{i}$ is the fitness value of chromosome and $N$ is the population size.

(ii) Crossover: in the literature, crossover rate varies between $50 \%$ and $95 \%$, and mutation rate varies between $5 \%$ and $70 \%$ [60, 61]. A single-point crossover operator is used in the crossover process. This is illustrated in Figure 12.

Step 7. GA-replace

Replacement is applied with the elitist strategy. The chromosome with the best fitness value is carried directly to the newly generated population.

(iii) Mutation: a single-point mutation is performed. The mutation procedure is shown in Figure 13, and
TABLE 5: Savings calculation.

\begin{tabular}{|c|c|c|}
\hline \multirow{2}{*}{ Savings calculation } & \multicolumn{2}{|c|}{$\begin{array}{l}\text { Savings in descending } \\
\text { order }\end{array}$} \\
\hline & $\begin{array}{c}\text { Customer } \\
i-j\end{array}$ & $\begin{array}{l}\text { Savings } \\
\text { value }\end{array}$ \\
\hline $\begin{array}{l}S_{16}=900=420+300-180 \\
\left(d_{10}+d_{06}-d_{16}=d_{01}+d_{60}-d_{16}\right)\end{array}$ & $S_{16}$ & 900 \\
\hline $\begin{array}{l}S_{12}=445=420+200-175 \\
\left(d_{10}+d_{02}-d_{12}=d_{01}+d_{20}-d_{12}\right)\end{array}$ & $S_{12}$ & 445 \\
\hline $\begin{array}{l}S_{46}=430=230+300-100 \\
\left(d_{40}+d_{06}-d_{46}=d_{04}+d_{60}-d_{46}\right)\end{array}$ & $S_{46}$ & 430 \\
\hline $\begin{array}{l}S_{56}=410=155+300-45 \\
\left(d_{50}+d_{06}-d_{56}=d_{05}+d_{60}-d_{56}\right)\end{array}$ & $S_{56}$ & 410 \\
\hline $\begin{array}{l}S_{15}=410=420+155-165 \\
\left(d_{10}+d_{05}-d_{15}=d_{01}+d_{50}-d_{15}\right)\end{array}$ & $S_{15}$ & 410 \\
\hline $\begin{array}{l}S_{14}=350=420+230-300 \\
\left(d_{10}+d_{04}-d_{14}=d_{01}+d_{40}-d_{14}\right)\end{array}$ & $S_{14}$ & 350 \\
\hline $\begin{array}{l}S_{45}=330=230+155-55 \\
\left(d_{40}+d_{05}-d_{45}=d_{04}+d_{40}-d_{45}\right)\end{array}$ & $S_{45}$ & 330 \\
\hline $\begin{array}{l}S_{26}=310=200+300-190 \\
\left(d_{20}+d_{06}-d_{26}=d_{02}+d_{60}-d_{26}\right)\end{array}$ & $S_{26}$ & 310 \\
\hline $\begin{array}{l}S_{13}=265=420+175-330 \\
\left(d_{10}+d_{03}-d_{13}=d_{01}+d_{30}-d_{13}\right)\end{array}$ & $S_{13}$ & 265 \\
\hline $\begin{array}{l}S_{35}=181=175+155-149 \\
\left(d_{30}+d_{05}-d_{35}=d_{03}+d_{50}-d_{35}\right)\end{array}$ & $S_{35}$ & 181 \\
\hline $\begin{array}{l}S_{36}=175=175+300-300 \\
\left(d_{30}+d_{06}-d_{36}=d_{03}+d_{60}-d_{36}\right)\end{array}$ & $S_{36}$ & 175 \\
\hline $\begin{array}{l}S_{25}=170=200+155-185 \\
\left(d_{20}+d_{05}-d_{25}=d_{02}+d_{50}-d_{25}\right)\end{array}$ & $S_{25}$ & 170 \\
\hline $\begin{array}{l}S_{34}=125=175+230-280 \\
\left(d_{30}+d_{04}-d_{34}=d_{03}+d_{40}-d_{34}\right)\end{array}$ & $S_{34}$ & 125 \\
\hline $\begin{array}{l}S_{23}=70=200+175-305 \\
\left(d_{20}+d_{03}-d_{23}=d_{02}+d_{30}-d_{23}\right)\end{array}$ & $S_{23}$ & 70 \\
\hline $\begin{array}{l}S_{24}=27=200+230-403 \\
\left(d_{20}+d_{04}-d_{24}=d_{02}+d_{40}-d_{24}\right)\end{array}$ & $S_{24}$ & 27 \\
\hline
\end{tabular}

a sample for mutation is shown in Figure 14, where a gene is randomly selected. Random numbers are generated between the range $[0,1]$. For mutation, 0.5 is accepted as a threshold value, and the following procedure is applied:

(1) If the gene distribution strategy value is crossdocking and generated a random number, that is, <0.5, direct shipment is assigned as the distribution strategy, else the milk run is assigned

(2) If the gene distribution strategy value is direct shipment and generated a random number, that is, $<0.5$, cross-docking is assigned as a distribution strategy, else the milk run is assigned

(3) If the gene distribution strategy value is milk run and generated a random number, that is, $<0.5$, cross-docking is assigned as a distribution strategy, else direct shipment is assigned

Step 8. GA-terminate algorithm

Maximum iteration number is used as the termination condition (iteration number $=1000$ ). 
TABLE 6: Modified savings results.

\begin{tabular}{|c|c|c|c|c|c|c|c|c|c|}
\hline \multirow{2}{*}{$S_{i j}$} & \multirow{2}{*}{ Savings } & \multirow{2}{*}{ Random number } & \multirow{2}{*}{ Route } & \multirow{2}{*}{ Total demand } & \multirow{2}{*}{$\begin{array}{c}\text { Total } \\
\text { distance }\end{array}$} & \multirow{2}{*}{$\begin{array}{c}\text { Vehicle } \\
\text { capacity type }\end{array}$} & \multirow{2}{*}{$\begin{array}{c}\text { Random } \\
\text { number }>0,90\end{array}$} & \multicolumn{2}{|c|}{ Violation } \\
\hline & & & & & & & & Vehicle capacity & Travel distance \\
\hline$S_{12}$ & 445 & 0,58 & $0-1-2-0$ & 30 & 795 & $30-3$ & & & \\
\hline$S_{46}$ & 430 & 0,61 & & 35 & 630 & $50-4$ & & & \\
\hline$S_{56}$ & 410 & 0,22 & $0-4-6-5-0$ & 45 & 675 & $50-4$ & & & \\
\hline$S_{16}$ & 900 & 0,99 & - & - & - & - & $x$ & & \\
\hline$S_{15}$ & 410 & 0,98 & & & & - & $x$ & $x$ & $x$ \\
\hline$S_{45}$ & 330 & 0,15 & - & - & - & - & & & \\
\hline$S_{26}$ & 310 & 0,77 & - & - & - & - & & & \\
\hline$S_{13}$ & 265 & 0,42 & & & 880 & - & & $x$ & \\
\hline$S_{14}$ & 350 & 0,92 & & & & - & $x$ & $x$ & $x$ \\
\hline$S_{36}$ & 175 & 0,73 & - & - & - & - & & & \\
\hline$S_{25}$ & 170 & 0,76 & & & & - & & $x$ & $x$ \\
\hline$S_{35}$ & 181 & 0,97 & & & & - & $x$ & $x$ & \\
\hline$S_{23}$ & 70 & 0,22 & & & & - & & $x$ & $x$ \\
\hline$S_{24}$ & 27 & 0,71 & & & & - & & $x$ & $x$ \\
\hline$S_{34}$ & 125 & 0,48 & & & 755 & - & & $x$ & \\
\hline
\end{tabular}

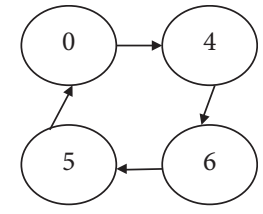

(a)

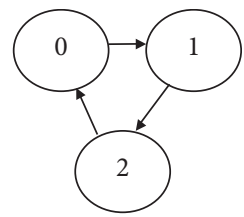

(b)

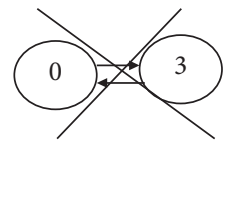

(c)

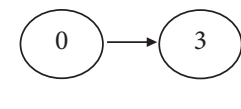

(d)

FIgURE 6: Routes created by the modified savings algorithm. (a) Route 1. (b) Route 2. (c) Route 3 canceled. (d) Direct shipment.

TABLE 7: Traditional savings results.

\begin{tabular}{|c|c|c|c|c|c|c|c|}
\hline \multirow{2}{*}{$S_{i j}$} & \multirow{2}{*}{ Savings } & \multirow{2}{*}{ Route } & \multirow{2}{*}{ Total demand } & \multirow{2}{*}{ Total distance } & \multirow{2}{*}{ Vehicle capacity type } & \multicolumn{2}{|c|}{ Violation } \\
\hline & & & & & & Vehicle capacity & Travel distance \\
\hline$S_{16}$ & 900 & & 40 & 720 & $50-4$ & & \\
\hline$S_{12}$ & 445 & $0-2-0$ & 20 & $\begin{array}{l}855 \\
400\end{array}$ & $25-2$ & $x$ & \\
\hline$S_{46}$ & 430 & & 45 & & $50-4$ & & $x$ \\
\hline$S_{56}$ & 410 & $0-1-6-5-0$ & 50 & 800 & $50-4$ & & \\
\hline$S_{15}$ & 410 & - & - & - & - & & \\
\hline$S_{14}$ & 350 & & & & - & $x$ & $x$ \\
\hline$S_{45}$ & 330 & & & & - & $x$ & $x$ \\
\hline$S_{26}$ & 310 & - & - & - & - & & \\
\hline$S_{13}$ & 265 & & & 885 & - & $x$ & \\
\hline$S_{35}$ & 181 & & & & - & $x$ & $x$ \\
\hline$S_{36}$ & 175 & - & - & - & - & & \\
\hline$S_{25}$ & 170 & & & & - & $x$ & $x$ \\
\hline$S_{34}$ & 125 & $0-3-4-0$ & 28 & 685 & $30-3$ & & \\
\hline$S_{23}$ & 70 & & 48 & & $50-4$ & & $x$ \\
\hline$S_{24}$ & 27 & & 48 & & $50-4$ & & $x$ \\
\hline
\end{tabular}

The flow of the new approach is shown in Figure 15. The pseudocode of the new approach is given below:

(1) [Step 1] Generate a random population

(i) Initialize population (population size $=100$ )

(ii) Assign distribution strategy to customers randomly
(2) [Step 2] If method = milk run, apply modified savings algorithm steps

(3) [Step 3] Else if method=direct shipment, apply direct procedure

(4) [Step 4] Else method=cross-docking, apply crossdocking procedure 


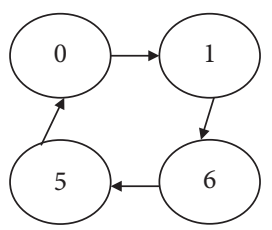

(a)

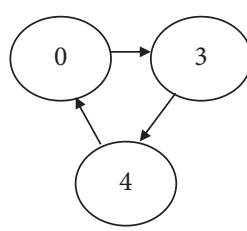

(b)

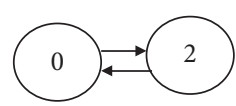

(c)

Figure 7: Routes created by the traditional savings algorithm. (a) Route 1. (b) Route 2. (c) Route 3.

TABLE 8: Savings obtained by the modified savings algorithm.

\begin{tabular}{|c|c|c|c|c|c|c|c|c|c|c|}
\hline \multirow[b]{2}{*}{ Route } & \multicolumn{3}{|c|}{ Traditional savings } & \multicolumn{6}{|c|}{ Modified savings } & \multirow[b]{2}{*}{ Savings cost $(\$ / \mathrm{km})$} \\
\hline & Distance & Vehicle cost & $\begin{array}{c}\text { Total } \\
\text { distance }\end{array}$ & $\begin{array}{l}\text { Total } \\
\text { cost }\end{array}$ & Route & Distance & $\begin{array}{c}\text { Vehicle } \\
\text { cost }\end{array}$ & $\begin{array}{c}\text { Total } \\
\text { distance }\end{array}$ & $\begin{array}{c}\text { Total } \\
\text { cost }\end{array}$ & \\
\hline $0-1-6-5-0$ & 800 & 172 & & & $0-4-6-5-0$ & 675 & 172 & & & \\
\hline $0-3-4-0$ & 685 & 137 & 1885 & 2317 & $0-1-2-0$ & 795 & 137 & 1645 & 2077 & 240 \\
\hline $0-2-0$ & 400 & 123 & & & $0-3$ & 175 & 123 & & & \\
\hline
\end{tabular}

\begin{tabular}{|c|c|c|c|c|c|c|c|c|c|}
\hline 3 & 3 & 3 & 3 & 3 & 3 & 1 & 1 & 1 & 2 \\
\hline 1 & 2 & 3 & 4 & 5 & 6 & 7 & 8 & 9 & 10 \\
\hline
\end{tabular}

FIGURE 8: The chromosome representation before applying the modified savings algorithm.

\begin{tabular}{|c|c|c|c|c|c|c|c|c|c|}
\hline 3 & 3 & 2 & 3 & 3 & 3 & 1 & 1 & 1 & 2 \\
\hline 1 & 2 & 3 & 4 & 5 & 6 & 7 & 8 & 9 & 10 \\
& & $\uparrow$ & & & & & & &
\end{tabular}

FIGURE 9: The repaired chromosome representation after applying the modified savings algorithm.

\begin{tabular}{|c|c|c|c|c|c|c|c|c|c|}
\hline 3 & 3 & 2 & 3 & 3 & 3 & 1 & 1 & 1 & 2 \\
\hline 1 & 2 & 3 & 4 & 5 & 6 & 7 & 8 & 9 & 10 \\
& & $\uparrow$ & & & & & & & $\uparrow$
\end{tabular}

FIgURE 10: Customers assigned to the direct shipment strategy.

\begin{tabular}{|c|c|c|c|c|c|c|c|c|c|}
\hline 3 & 3 & 2 & 3 & 3 & 3 & 1 & 1 & 1 & 2 \\
\hline 1 & 2 & 3 & 4 & 5 & 6 & 7 & 8 & 9 & 10 \\
\hline
\end{tabular}

FIgURE 11: Customers assigned to the cross-docking strategy.

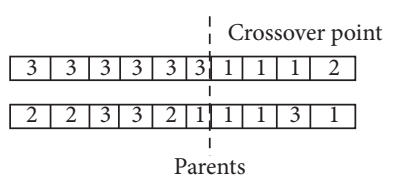

\begin{tabular}{l}
\begin{tabular}{|c|c|c|c|c|c|c|c|c|c|}
\hline 3 & 3 & 3 & 3 & 3 & 3 & 1 & 1 & 3 & 1 \\
\hline 2 & 2 & 3 & 3 & 2 & 1 & 1 & 1 & 1 & 2 \\
\hline \multicolumn{8}{|c|}{ Offspring }
\end{tabular} \\
\hline
\end{tabular}

FIGURE 12: Crossover procedure. (1) Cross-docking; (2) direct shipment; (3) milk run.
(5) [Step 5] Evaluate the fitness value

(i) Calculate the total distribution costs

(ii) Rank the costs in descending order

(6) [Step 6] Create new population

(i) [Selection] Select two parent chromosomes according to their fitness value

(ii) [Crossover] Apply single-point crossover to form a new offspring

(iii) [Mutation] Apply a single-point mutation to form a new offspring

(iv) [Placement] Place new offspring in a new population

(7) [Step 7] Stop creating a new population. If population size $=100$, finish forming a new offspring else go to Step 6

(8) [Step 8] Replace-Apply the elitist strategy and use newly generated population

(9) [Step 9] Terminate algorithm if iteration number = maximum iteration number, finish algorithm, and return the best solution, else go to Step 2

\section{Case Study of the Proposed Algorithm}

In this section, the effectiveness of the proposed algorithm is confirmed by a case study. The case study is conducted on a global electronics manufacturing company. The company's products are mainly electronic components. The company has 380,000 employees and makes 1,502,000,000 deliveries annually. Following steady growth, the company management is trying to find a better route planning solution for its distribution network to meet the market demands and extend its business scope.

For the case study, a project team was established with the SCM director (15 years of experience), the business analyst (10 years of experience), and the authors. Some of the company's staff was invited to attend the meetings when 


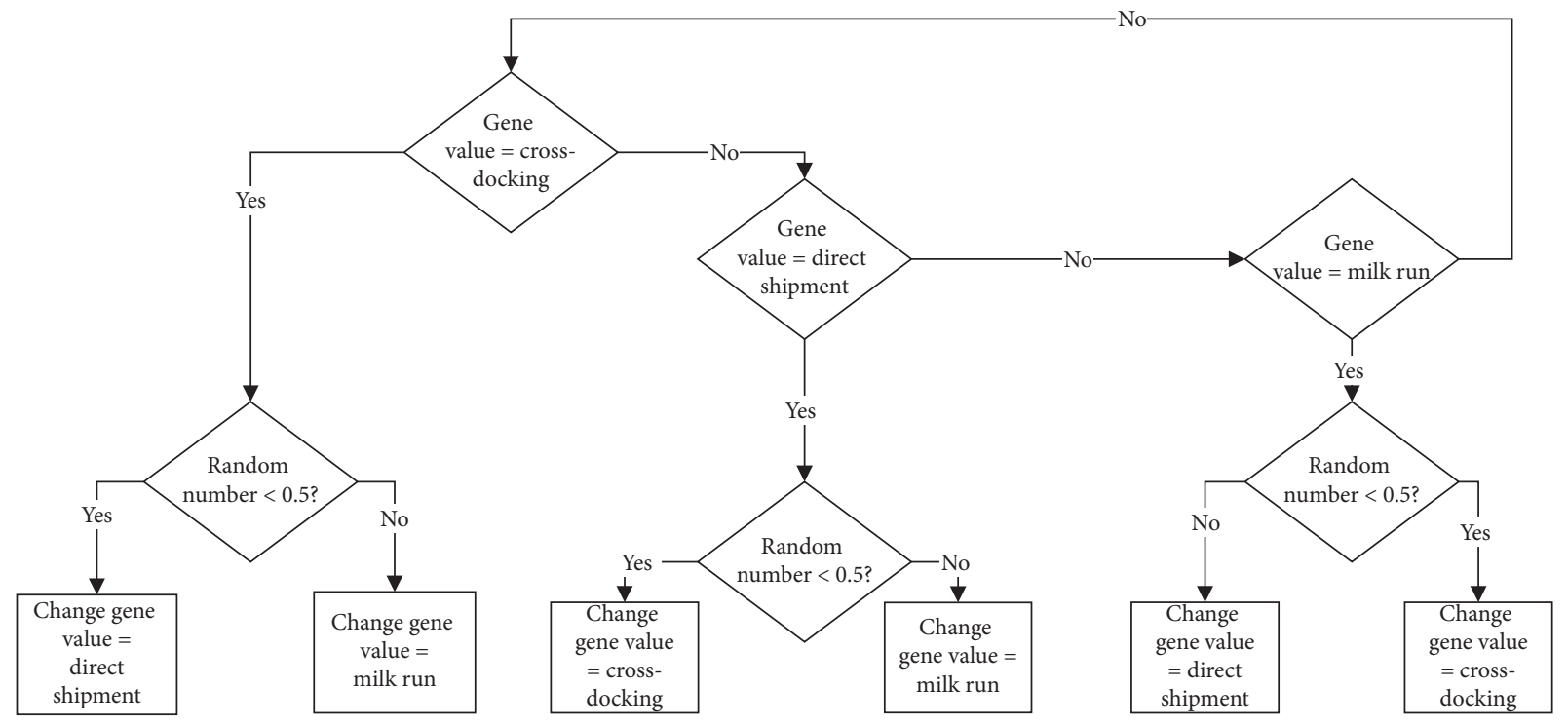

Figure 13: Mutation procedure.

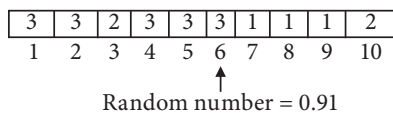

(a)

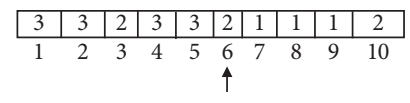

(b)

FIgURe 14: Mutation sample. (a) Before mutation. (b) After mutation.

needed. One of the authors, a former project manager, acted as a consultant (15 years of experience) for the value study. The team met biweekly ( 4 hours per meeting) to discuss the distribution process and agreed to work on the process. Figure 16 presents a sample of the distribution network that is worked on.

A data sample involving up to 50 customer's distribution requests is used as a problem dataset. Table 9 presents the data sample, including shipment size, the Cartesian coordinates of the customer locations, and direct shipment costs from the cross-docking center for each customer request. Table 10 presents vehicle characteristics, and Table 11 presents other characteristics.

Lingo 15.0 package program is used to obtain the optimal solutions. The software language used in the development of the proposed algorithm is Visual Studio $2013 \mathrm{C}$ sharp. Minitab 15 and SPSS 17.0 package programs are used for performing statistical tests and evaluating statistical results. In addition to this, Minitab 15 is used to apply the Taguchi method. A 64-bit PC with Core i-7-8550U CPU and $8 \mathrm{~GB}$ RAM is used to solve the dataset sample.

The genetic algorithm was run 30 times for each data sample. In the determination of the genetic algorithm parameters, the literature was used. In the literature, the population size ranges from 20 to 100 [58], the crossover rate ranges from $50 \%$ to $95 \%$, and the mutation rate ranges from $5 \%$ to $70 \%[60,61]$. Therefore, five levels were determined for these three factors. They are for population size, 20, 30, 40, 50, 100; for crossover rate, $0.5,0.6,0.7,0.8,0.9$; and for mutation rate, $0.01,0.05,0.1,0.2,0.3$. The Taguchi method, an experimental design technique, is used to determine the optimum parameters because it would take too long to test these parameter combinations for each customer data sample.

5.1. Optimization of GA Parameters with Taguchi Method. The Taguchi method is a statistical method developed by Taguchi and Konishi [62]. The Taguchi method is a helpful method for determining the best combination of different parameters and levels. Taguchi suggests that there is a loss function value converted to a signal-to-noise ratio $(\mathrm{S} / \mathrm{N})$ to measure performance characteristics deviations from the target value. In the analysis of the $\mathrm{S} / \mathrm{N}$ ratio, there are three categories of performance characteristics: nominal best, largest best, and smallest best.

5.1.1. Determination of Control Factors and Levels. At this stage, the factors and levels that affect performance characteristics are determined. Population size, crossover rate, and mutation rate are the control factors. There are five levels for each factor. Table 12 shows the levels defined for the factors.

5.1.2. Selection of Orthogonal Array. The most important feature of the orthogonal order is to be able to evaluate factors with a minimum number of tests. In this paper, an L25 orthogonal array is used. 


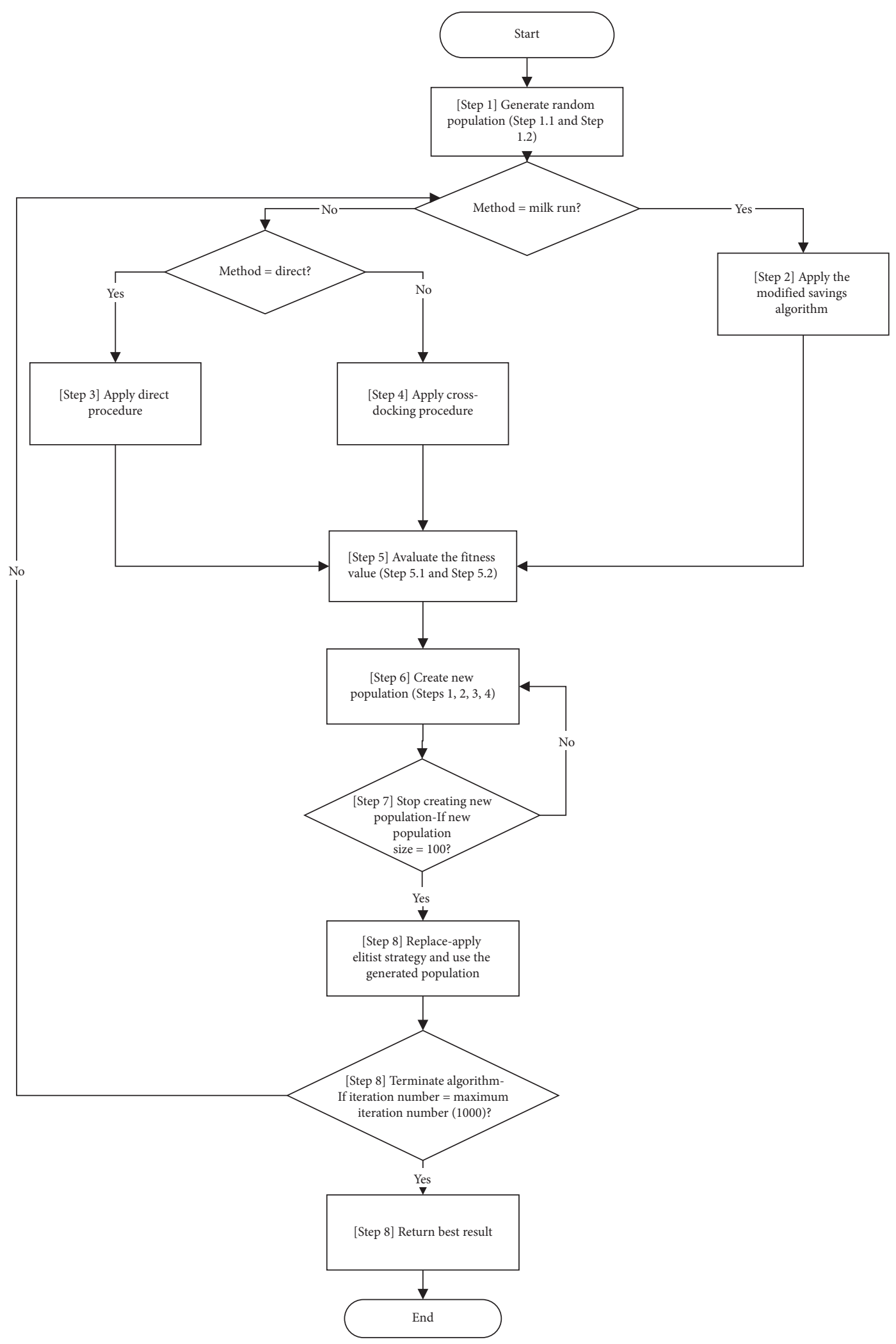

FIGURE 15: The flow of the proposed hybrid algorithm. 


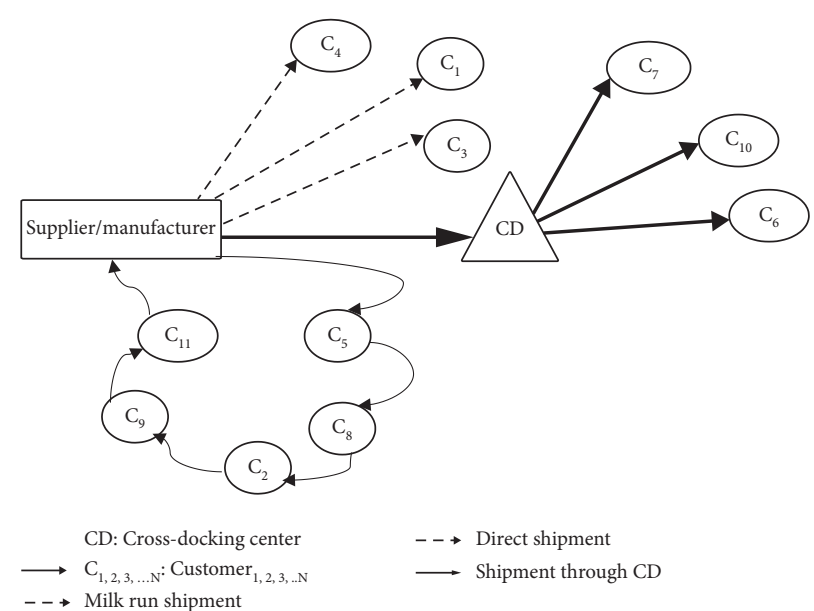

Figure 16: A sample of the distribution network for the case study.

TABle 9: Dataset sample involving up to 50 distribution requests.

\begin{tabular}{|c|c|c|c|c|}
\hline \multirow{2}{*}{ Customer number } & \multirow{2}{*}{ Load $\left(\mathrm{m}^{3}\right)$} & \multicolumn{2}{|c|}{ Customer location } & \multirow{2}{*}{ Direct shipment cost from the cross-docking center (load $* 1.5 \$$ ) } \\
\hline & & $X$ coordinate & $Y$ coordinate & \\
\hline 1 & 10 & 101 & 195 & 15 \\
\hline 2 & 15 & 184 & 115 & 22,5 \\
\hline 3 & 13 & 140 & 49 & 19,5 \\
\hline 4 & 10 & 110 & 98 & 15 \\
\hline 5 & 26 & 114 & 52 & 39 \\
\hline 6 & 2 & 184 & 189 & 3 \\
\hline 7 & 25 & 83 & 50 & 37,5 \\
\hline 8 & 4 & 298 & 99 & 6 \\
\hline 9 & 16 & 75 & 260 & 24 \\
\hline 10 & 18 & 250 & 38 & 27 \\
\hline 11 & 24 & 94 & 298 & 36 \\
\hline 12 & 12 & 246 & 41 & 18 \\
\hline 13 & 11 & 167 & 58 & 16,5 \\
\hline 14 & 32 & 99 & 255 & 48 \\
\hline 15 & 8 & 270 & 80 & 12 \\
\hline 16 & 17 & 98 & 256 & 25,5 \\
\hline 17 & 13 & 217 & 167 & 19,5 \\
\hline 18 & 10 & 200 & 180 & 15 \\
\hline 19 & 40 & 160 & 64 & 60 \\
\hline 20 & 42 & 154 & 128 & 63 \\
\hline 21 & 50 & 207 & 57 & 75 \\
\hline 22 & 17 & 187 & 265 & 25,5 \\
\hline 23 & 29 & 168 & 234 & 43,5 \\
\hline 24 & 12 & 292 & 291 & 18 \\
\hline 25 & 15 & 189 & 118 & 22,5 \\
\hline 26 & 38 & 148 & 261 & 57 \\
\hline 27 & 50 & 155 & 240 & 75 \\
\hline 28 & 23 & 287 & 80 & 34,5 \\
\hline 29 & 12 & 81 & 243 & 18 \\
\hline 30 & 18 & 156 & 56 & 27 \\
\hline 31 & 19 & 43 & 221 & 28,5 \\
\hline 32 & 22 & 193 & 119 & 33 \\
\hline 33 & 6 & 70 & 269 & 9 \\
\hline 34 & 19 & 290 & 231 & 28,5 \\
\hline 35 & 29 & 253 & 247 & 43,5 \\
\hline 36 & 33 & 136 & 86 & 49,5 \\
\hline 37 & 20 & 228 & 138 & 30 \\
\hline 38 & 40 & 80 & 209 & 60 \\
\hline 39 & 9 & 298 & 272 & 13,5 \\
\hline
\end{tabular}


TABle 9: Continued.

\begin{tabular}{lcccc}
\hline \multirow{2}{*}{ Customer number } & Load $\left(\mathrm{m}^{3}\right)$ & \multicolumn{2}{c}{ Customer location } & Direct shipment cost from the cross-docking center (load * 1.5 \$) \\
& & $X$ coordinate & $Y$ coordinate & Di, \\
40 & 21 & 65 & 262 & 28,5 \\
41 & 19 & 148 & 229 & 31,5 \\
42 & 21 & 31 & 252 & 22,5 \\
43 & 15 & 89 & 56 & 18 \\
44 & 12 & 182 & 100 & 22,5 \\
45 & 15 & 76 & 180 & 21 \\
46 & 16 & 176 & 127 & 33 \\
47 & 14 & 126 & 194 & 27 \\
48 & 22 & 270 & 130 & 25,5 \\
49 & 18 & 53 & 56 & 25 \\
50 & 17 & 169 & 250 & \\
\hline
\end{tabular}

Manufacturer/supplier Cartesian coordinates: $X=125, Y=35$; cross-dock Cartesian coordinates: $X=400, Y=200$.

TABLe 10: Vehicle characteristics.

\begin{tabular}{lcc}
\hline Vehicle type & Capacity $\left(\mathrm{m}^{3}\right)$ & Vehicle cost $(\$)$ \\
\hline 1 & 9 & 86 \\
2 & 25 & 123,8 \\
3 & 30 & 137,6 \\
4 & 50 & 172 \\
\hline
\end{tabular}

TABLE 11: Other characteristics.

\begin{tabular}{lccc}
\hline $\begin{array}{l}\text { Truck capacity for } \\
\text { cross-docking }\left(\mathrm{m}^{3}\right)\end{array}$ & Truck fixed cost for cross-docking $(\$)$ & Milk run stop cost $(\$)$ & Milk run limited tour distance $(\mathrm{km})$ \\
\hline 45 & 172 & 9,6 & 900 \\
\hline
\end{tabular}

TABLE 12: Control factors determined at different levels.

\begin{tabular}{lccccc}
\hline Factors & Level 1 & Level 2 & Level 3 & Level 4 & Level 5 \\
\hline Population size & 20 & 30 & 40 & 50 & 100 \\
Crossover rate & 0.50 & 0.60 & 0.70 & 0.80 & 0.90 \\
Mutation rate & 0.01 & 0.05 & 0.1 & 0.2 & 0.3 \\
\hline
\end{tabular}

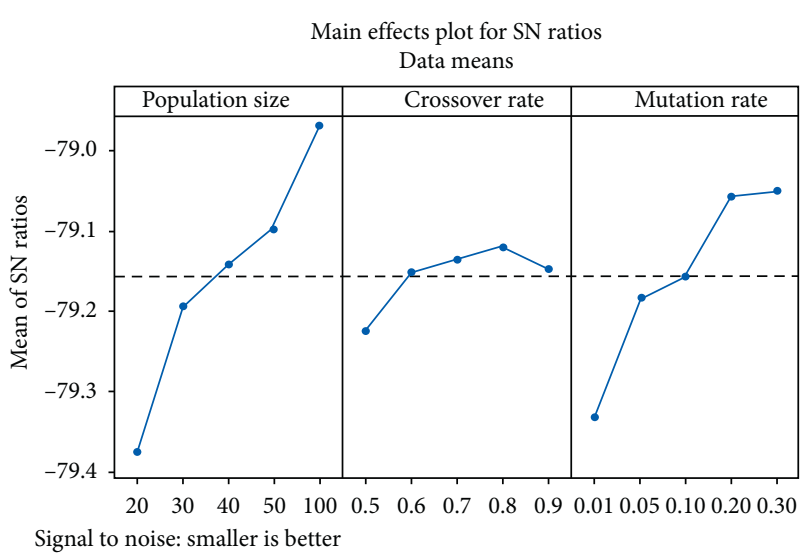

FIGURE 17: S/N result graph for Taguchi experiments.

5.1.3. Calculation of Loss Function and $S / N$ Ratio. The proposed algorithm tries to minimize the $Z$ value, which is the objective function value. The function value is used to calculate the loss function value. The objective function is the smallest best for this paper.

The $\mathrm{S} / \mathrm{N}$ ratio is calculated using the formula in equation (16) where the smallest is the best:

$$
\mathrm{S} / \mathrm{N}=-10 \log \left(\frac{1}{n} \sum_{i=1}^{n} y i^{2}\right)
$$

5.1.4. Construction and Analysis of Experiments. Experiments are determined by the Taguchi method. L25 orthogonal array is applied, and 25 experiments are executed. For one customer data sample, each experiment is repeated 30 times to obtain the best values in the solution of the proposed algorithm. Since it is the minimization problem, the values with the biggest $\mathrm{S} / \mathrm{N}$ ratio are the best values. According to Figure 17, the best values for population size, crossover rate, and mutation rate, respectively, are $100,0.8$, and 0.3 . 
TABLE 13: Solutions of the data samples.

\begin{tabular}{|c|c|c|c|c|c|c|c|c|c|}
\hline $\begin{array}{l}\text { Data } \\
\text { sample size } \\
\text { (number) } \\
\text { C: } \\
\text { customer }\end{array}$ & $\begin{array}{l}\text { Optimal } \\
\text { cost }(\$)\end{array}$ & $\begin{array}{l}\text { Optimal } \\
\text { CPU (s) S: } \\
\text { second }\end{array}$ & $\begin{array}{l}\text { Heuristic } \\
\text { solution } \\
(\$)\end{array}$ & $\begin{array}{l}\text { Heuristic } \\
\text { CPU (s) S: } \\
\text { second }\end{array}$ & Milk run tour(s) & $\begin{array}{l}\text { Direct } \\
\text { tour(s) }\end{array}$ & $\begin{array}{l}\text { Customer(s) } \\
\text { serviced by } \\
\text { cross-docking } \\
\text { shipment }\end{array}$ & $\begin{array}{l}\text { The fleet } \\
\text { composition } \\
\text { (capacity }\left(\mathrm{m}^{3}\right) \text { - } \\
\text { shipment type) } \\
\text { M: milk run, D: } \\
\text { direct shipment }\end{array}$ & $\begin{array}{l}\text { The } \\
\text { number of } \\
\text { a used } \\
\text { vehicle for } \\
\text { milk run } \\
\text { and direct } \\
\text { shipment }\end{array}$ \\
\hline $4 \mathrm{C}$ & 587,40 & 1,00 & 587,40 & 0,06 & $0-4-1-2-3-0$ & & & $50-\mathrm{M}$ & 1 \\
\hline $5 \mathrm{C}$ & 745,00 & 1,00 & 745,00 & 0,03 & $0-3-2-1-4-0$ & $0-5$ & & 50-M, 30-D & 2 \\
\hline $6 \mathrm{C}$ & 796,60 & 5,00 & 796,63 & 0,08 & $0-4-1-6-2-3-0$ & $0-5$ & & 50-M, 30-D & 2 \\
\hline 7C & 965,40 & 8,00 & 965,62 & 0,11 & $0-3-2-6-1-4-0$ & $\begin{array}{lll}0-5 & 0-7\end{array}$ & & $\begin{array}{c}\text { 50-M, 25-D, } \\
\text { 30-D }\end{array}$ & 3 \\
\hline $8 \mathrm{C}$ & 981,50 & 30,00 & 981,51 & 0,08 & $0-5-3-0$ & $0-7$ & $1,2,4,6,8$ & 50-M, 25-D & 2 \\
\hline $9 \mathrm{C}$ & 1193,90 & 266,00 & 1194,03 & 0,06 & $0-2-4-7-0$ & $0-5$ & $1,3,6,8,9$ & 50-M, 30-D & 2 \\
\hline $10 \mathrm{C}$ & 1409,20 & 8330,00 & 1409,31 & 0,10 & $0-10-2-3-0$ & $\begin{array}{ll}0-5 & 0-7\end{array}$ & $2,5,7,9,10$ & $\begin{array}{c}\text { 50-M, 25-D, } \\
\text { 30-D }\end{array}$ & 3 \\
\hline $11 \mathrm{C}$ & 1633,10 & 25211,00 & 1633,10 & 0,08 & $0-3-4-5-0$ & $0-7$ & $\begin{array}{c}2,3,7,9,10,11, \\
12\end{array}$ & 50-M, 25-D & 2 \\
\hline $12 \mathrm{C}$ & 1849,00 & 203009,00 & 1849,10 & 0,13 & $0-5-3-0-0-7-4-2-0$ & & $\begin{array}{c}2,7,9,10,11 \\
12,13\end{array}$ & $50-\mathrm{M}, 50-\mathrm{M}$ & 2 \\
\hline $13 \mathrm{C}$ & - & - & 1900,80 & 0,18 & $0-4-2-13-3-0$ & $\begin{array}{lll}0-5 & 0-7\end{array}$ & $\begin{array}{c}1,6,8,9,10,11 \\
12\end{array}$ & $\begin{array}{c}\text { 50-M, 25-D, } \\
\text { 30-D }\end{array}$ & 3 \\
\hline $14 \mathrm{C}$ & - & - & 2294,80 & 0,19 & $0-4-2-13-3-0$ & $\begin{array}{c}0-50-7 \\
0-14\end{array}$ & $\begin{array}{c}1,6,8,9,10,11 \\
12\end{array}$ & $\begin{array}{c}\text { 50-M, 25-D, } \\
30-\mathrm{D}, 50-\mathrm{D}\end{array}$ & 4 \\
\hline $15 \mathrm{C}$ & - & - & 2399,68 & 0,15 & 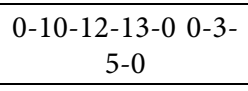 & $0-7 \quad 0-14$ & $\begin{array}{c}1,2,4,6,8,9 \\
11,15\end{array}$ & $\begin{array}{c}\text { 50-M, 50-M, } \\
25-\mathrm{D}, 50-\mathrm{D}\end{array}$ & 4 \\
\hline $16 \mathrm{C}$ & - & - & 2561,83 & 0,22 & $\begin{array}{c}0-12-10-15-13-0 \\
0-5-4-3-0\end{array}$ & $0-7 \quad 0-14$ & $\begin{array}{c}1,2,6,8,9,11, \\
16\end{array}$ & $\begin{array}{c}\text { 50-M, 50-M, } \\
25-\mathrm{D}, 50-\mathrm{D}\end{array}$ & 4 \\
\hline $17 \mathrm{C}$ & - & - & 2788,97 & 0,15 & $0-3-13-5-0$ & $\begin{array}{c}0-20-7 \\
0-14\end{array}$ & $\begin{array}{c}1,4,6,8,9,10 \\
11,12,15,16 \\
17\end{array}$ & $\begin{array}{c}\text { 50-M, 25-D, } \\
25-\mathrm{D}, 50-\mathrm{D}\end{array}$ & 4 \\
\hline $18 \mathrm{C}$ & - & - & 2859,80 & 0,30 & $0-4-2-13-3-0$ & $\begin{array}{c}0-50-7 \\
0-14\end{array}$ & $\begin{array}{c}1,6,8,9,10,11 \\
12,15,16,17 \\
18\end{array}$ & $\begin{array}{c}\text { 50-M, 25-D, } \\
30-\mathrm{D}, 50-\mathrm{D}\end{array}$ & 4 \\
\hline $19 \mathrm{C}$ & - & - & 3076,80 & 0,22 & $0-4-2-13-3-0$ & $\begin{array}{c}0-50-7 \\
0-140- \\
19\end{array}$ & $\begin{array}{c}1,6,8,9,10,11 \\
12,15,16,17 \\
18\end{array}$ & $\begin{array}{c}\text { 50-M, 25-D, } \\
30-\mathrm{D}, 50-\mathrm{D}, 50- \\
\mathrm{D}\end{array}$ & 5 \\
\hline $20 \mathrm{C}$ & - & - & 3345,80 & 0,32 & $0-4-2-13-3-0$ & 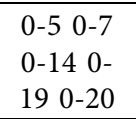 & $\begin{array}{c}1,6,8,9,10,11 \\
12,15,16,17 \\
18\end{array}$ & $\begin{array}{c}\text { 50-M, 25-D, } \\
30-\mathrm{D}, 50-\mathrm{D}, 50- \\
\mathrm{D}, 50-\mathrm{D}\end{array}$ & 6 \\
\hline $21 \mathrm{C}$ & - & - & 3602,80 & 0,27 & $0-4-2-13-3-0$ & $\begin{array}{c}0-50-7 \\
0-140- \\
190-20 \\
0-21 \\
\end{array}$ & $\begin{array}{c}1,6,8,9,10,11 \\
12,15,16,17 \\
18\end{array}$ & $\begin{array}{c}\text { 50-M, 25-D, } \\
30-\mathrm{D}, 50-\mathrm{D}, 50- \\
\mathrm{D}, 50-\mathrm{D}, 50-\mathrm{D}\end{array}$ & 7 \\
\hline $22 \mathrm{C}$ & - & - & 3831,04 & 0,33 & $\begin{array}{c}0-10-12-2-0 \\
13-5-0\end{array}$ & $\begin{array}{lll}0-7 & 0 & -14 \\
0-19 & 0- \\
20 & 0 & -21 \\
\end{array}$ & $\begin{array}{c}1,4,6,8,9,11 \\
15,16,17,18 \\
22\end{array}$ & $\begin{array}{c}\text { 50-M, 50-M, } \\
25-\mathrm{D}, 50-\mathrm{D}, 50- \\
\mathrm{D}, 50-\mathrm{D}, 50-\mathrm{D}\end{array}$ & 7 \\
\hline $23 \mathrm{C}$ & - & - & 4141,68 & 1,00 & 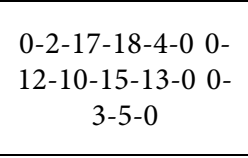 & 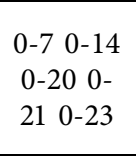 & $\begin{array}{c}1,6,8,9,11,16 \\
22\end{array}$ & $\begin{array}{c}\text { 50-M, 50-M, } \\
50-\mathrm{M}, 25-\mathrm{D} \\
\text { 50-D, 50-D, 50- } \\
\mathrm{D}, 30-\mathrm{D}\end{array}$ & 8 \\
\hline $25 \mathrm{C}$ & - & - & 4475,53 & 0,45 & 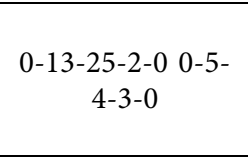 & 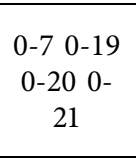 & $\begin{array}{c}1,6,8,9,10,11 \\
12,14,15,16 \\
17,18,22,23 \\
24\end{array}$ & $\begin{array}{c}\text { 50-M, 50-M, } \\
25-\mathrm{D}, 50-\mathrm{D}, 50- \\
\text { D, 50-D }\end{array}$ & 6 \\
\hline
\end{tabular}


TABle 13: Continued.

\begin{tabular}{|c|c|c|c|c|c|c|c|c|c|}
\hline $\begin{array}{l}\text { Data } \\
\text { sample size } \\
\text { (number) } \\
\text { C: } \\
\text { customer }\end{array}$ & $\begin{array}{l}\text { Optimal } \\
\text { cost }(\$)\end{array}$ & $\begin{array}{l}\text { Optimal } \\
\text { CPU (s) S: } \\
\text { second }\end{array}$ & $\begin{array}{l}\text { Heuristic } \\
\text { solution } \\
(\$)\end{array}$ & $\begin{array}{l}\text { Heuristic } \\
\text { CPU (s) S: } \\
\text { second }\end{array}$ & Milk run tour(s) & $\begin{array}{l}\text { Direct } \\
\text { tour(s) }\end{array}$ & $\begin{array}{l}\text { Customer(s) } \\
\text { serviced by } \\
\text { cross-docking } \\
\text { shipment }\end{array}$ & $\begin{array}{c}\text { The fleet } \\
\text { composition } \\
\text { (capacity }\left(\mathrm{m}^{3}\right)- \\
\text { shipment type) } \\
\text { M: milk run, D: } \\
\text { direct shipment }\end{array}$ & $\begin{array}{l}\text { The } \\
\text { number of } \\
\text { a used } \\
\text { vehicle for } \\
\text { milk run } \\
\text { and direct } \\
\text { shipment }\end{array}$ \\
\hline $30 \mathrm{C}$ & - & - & 5853,24 & 2,34 & $\begin{array}{c}0-10-12-30-0 \\
0-4-17-2-13-0 \\
0-3-5-0\end{array}$ & $\begin{array}{c}0-19 \\
0-20 \\
0-23 \\
0-26 \\
0-27 \\
0-28 \\
0-7 \\
0-21 \\
\end{array}$ & $\begin{array}{c}1,6,8,9,11,14 \\
15,16,18,22 \\
24,25,29\end{array}$ & $\begin{array}{c}50-\mathrm{M}, 50-\mathrm{M}, \\
50-\mathrm{M}, 50-\mathrm{D} \\
50-\mathrm{D}, 30-\mathrm{D}, 50- \\
\mathrm{D}, 50-\mathrm{D}, 25-\mathrm{D} \\
25-\mathrm{D}, 50-\mathrm{D}\end{array}$ & 11 \\
\hline $35 \mathrm{C}$ & - & - & 6982,65 & 2,80 & 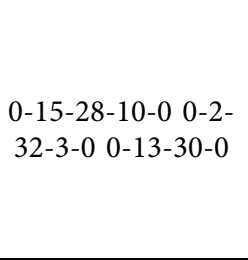 & 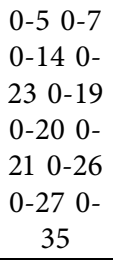 & $\begin{array}{c}1,4,6,8,9,11 \\
12,16,17,18 \\
22,24,25,29 \\
31,33,34\end{array}$ & $\begin{array}{c}50-\mathrm{M}, 50-\mathrm{M}, \\
30-\mathrm{M}, 30-\mathrm{D} \\
25-\mathrm{D}, 50-\mathrm{D}, 30- \\
\mathrm{D}, 50-\mathrm{D}, 50-\mathrm{D} \\
50-\mathrm{D}, 50-\mathrm{D}, 50- \\
\quad \mathrm{D}, 30-\mathrm{D}\end{array}$ & 13 \\
\hline $40 \mathrm{C}$ & - & - & 8081,06 & 6,45 & 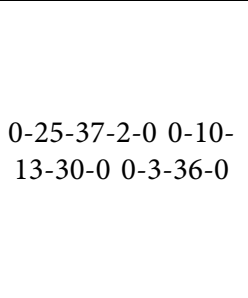 & $\begin{array}{ccc}0-5 & 0-7 \\
0-14 & 0- \\
23 & 0-19 \\
0-20 & 0- \\
21 & 0-26 \\
0-27 & 0- \\
28 & 0-32 \\
0 & 0-38\end{array}$ & $\begin{array}{c}1,4,6,8,9,11 \\
12,15,16,17 \\
18,22,24,29 \\
31,33,34,35 \\
39,40\end{array}$ & $\begin{array}{c}50-\mathrm{M}, 50-\mathrm{M}, \\
50-\mathrm{M}, 30-\mathrm{D}, \\
25-\mathrm{D}, 50-\mathrm{D}, 30- \\
\mathrm{D}, 50-\mathrm{D}, 50-\mathrm{D}, \\
50-\mathrm{D}, 50-\mathrm{D}, 50- \\
\mathrm{D}, 25-\mathrm{D}, 25-\mathrm{D}, \\
50-\mathrm{D}\end{array}$ & 15 \\
\hline $45 \mathrm{C}$ & - & - & 8958,50 & 6,09 & 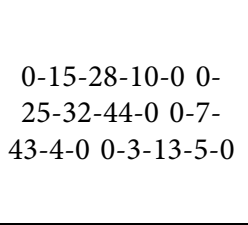 & 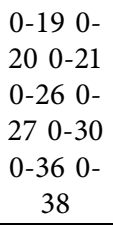 & $\begin{array}{c}1,2,6,8,9,11, \\
12,14,16,17 \\
18,22,23,24 \\
29,31,33,34 \\
35,39,40,41 \\
42,45\end{array}$ & $\begin{array}{c}50-\mathrm{M}, 50-\mathrm{M}, \\
50-\mathrm{M}, 50-\mathrm{M}, \\
50-\mathrm{D}, 50-\mathrm{D}, 50- \\
\mathrm{D}, 25-\mathrm{D}, 50-\mathrm{D}, \\
50-\mathrm{D}, 50-\mathrm{D}, 50- \\
\mathrm{D}\end{array}$ & 12 \\
\hline $50 \mathrm{C}$ & - & - & 10092,87 & 10,16 & 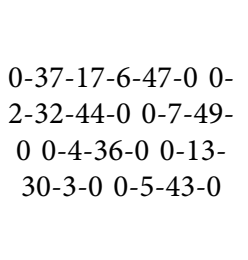 & 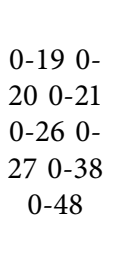 & $\begin{array}{c}1,8,9,10,11 \\
12,14,15,16 \\
18,22,23,24 \\
25,28,29,31 \\
33,34,35,39 \\
40,41,42,45 \\
46\end{array}$ & $\begin{array}{c}50-\mathrm{M}, 50-\mathrm{M}, \\
50-\mathrm{M}, 50-\mathrm{M}, \\
50-\mathrm{M}, 50-\mathrm{M}, \\
50-\mathrm{D}, 50-\mathrm{D}, 50- \\
\mathrm{D}, 50-\mathrm{D}, 50-\mathrm{D} \\
25-\mathrm{D}, 50-\mathrm{D}\end{array}$ & 13 \\
\hline
\end{tabular}

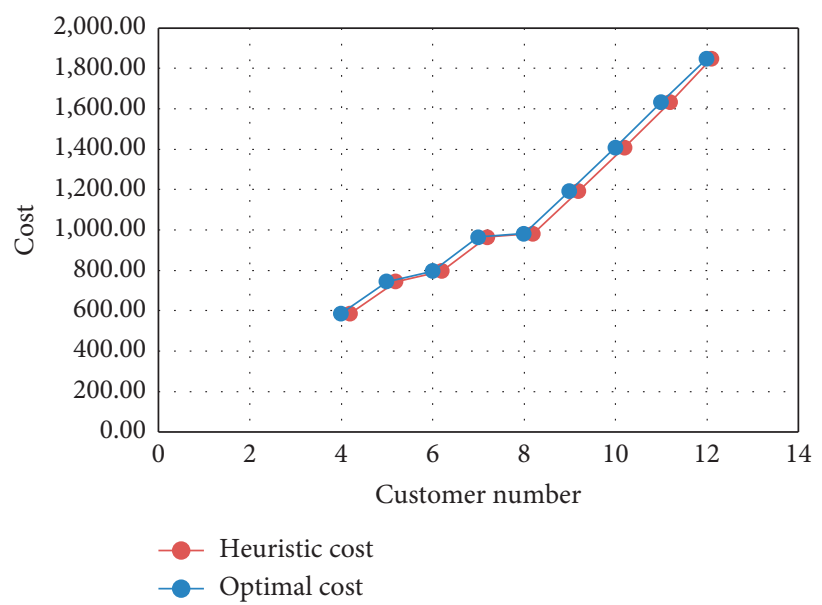

Figure 18: The comparison of solutions. 


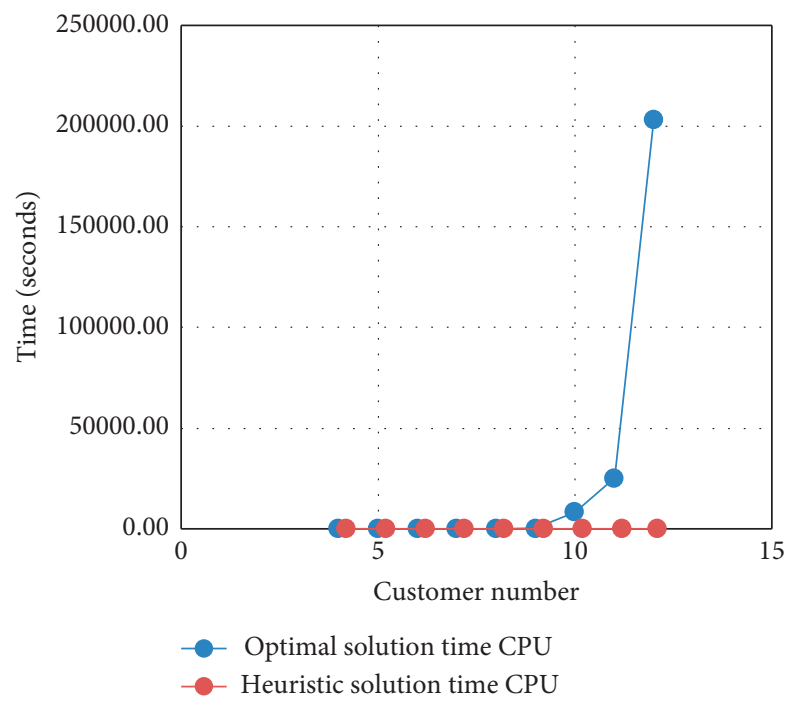

Figure 19: The comparison of CPU run times.

\begin{tabular}{|c|c|c|c|c|c|}
\hline \multicolumn{6}{|c|}{ Tests of normality } \\
\hline & \multicolumn{3}{|c|}{ Kolmogorov-Smirnova } & \multicolumn{2}{|l|}{ Shapiro-Wilk } \\
\hline & Statistic & $\mathrm{d} f$ & Sig. & Statistic $\mathrm{d} f$ & Sig. \\
\hline Difference value between solutions & 0.237 & 9 & 0.155 & 0.843 & 0.063 \\
\hline
\end{tabular}

Figure 20: Tests of normality results.

\begin{tabular}{|c|c|c|c|c|c|c|c|c|}
\hline \multicolumn{9}{|c|}{ Paired samples test } \\
\hline \multicolumn{9}{|c|}{ Paired differences } \\
\hline & \multicolumn{8}{|c|}{$\begin{array}{l}\text { 95\% Confidence interval of the } \\
\text { difference }\end{array}$} \\
\hline & Mean & $\begin{array}{c}\text { Std. } \\
\text { deviation }\end{array}$ & $\begin{array}{l}\text { Std. error } \\
\text { mean }\end{array}$ & Lower & Upper & $t$ & $\mathrm{~d} f$ & Sig. (2-tailed) \\
\hline $\begin{array}{l}\text { Pair } 1 \text { optimal solution- } \\
\text { heuristic solution }\end{array}$ & -0.06667 & 0.07778 & 0.02593 & -0.12646 & -0.00688 & -2.571 & 8 & 0.033 \\
\hline
\end{tabular}

FIgURE 21: Paired samples test results.

5.2. Computational Results and Statistical Analysis. This section presents the solutions of the data sample shown in Table 9 and statistical analysis for comparing the solutions. The solutions of the data samples are summarized in Table 13.

The solutions for the data sample involving up to 12 customers are created with both the optimization model and the proposed heuristic algorithm. As we can see from Table 13, the optimal time solution of the data sample involving up to 12 customers is 203009 seconds and that is nearly three days. Because of the long solution time, the solutions for the data sample involving more than 12 customers are created with the proposed heuristic algorithm. The comparisons of solutions are depicted in Figure 18. The two methods have given similar solutions for small-size samples.

Figure 19 shows the CPU run times for both methods. It can be observed that for small-size samples, the two methods have approximately the same running time. For the largesize samples, the optimization method's running time increases exponentially. So for large-size samples, the heuristic method is necessary to obtain solutions within a reasonable time.

The paired sample $t$-test is applied for the data samples involving up to 12 customers to compare the solutions. Before applying this test, the Kolmogorov-Smirnov test has been applied to control normality.

As shown in Figure 20, the significance level (Sig.) is 0.155 for the Kolmogorov-Smirnov test, and 0.063 for the Shapiro-Wilk test. These values are greater than 0.05 $(p>0.05)$, so the paired sample $t$-test can be applied for comparing solutions. In Figure 21, the significance value is 0.033 . Since the value is greater than $0.01(p>0.01)$, the null hypothesis is not rejected. Therefore, the two solutions produce similar solutions. It can be concluded from the 
statistical test that the proposed heuristic algorithm can produce good solutions.

\section{Conclusions}

Distribution plays an important role in supply chain management. Milk run added distribution network models reduce the number of vehicles and travel distances by increasing the loading rates at the possible levels. This kind of mixed logistics model requires accurate management based on the operational plan and a suitable combination of delivery methods to increase distribution reliability. The overall supply chain cost can be minimized by using an optimized mixed system.

In the literature, a few studies address a mixed delivery system, which consists of three delivery modes: milk run, direct shipment, and cross-docking shipment. Additionally, there is no developed heuristic solution based on Clarke and Wright's algorithm and the genetic algorithm to solve this mixed delivery network problem. This paper develops a "modified" savings-based genetic algorithm which is called distribution strategy selection and vehicle routing hybrid algorithm (DSSVRHA). Our algorithm contributes a new hybrid solution to the literature in order to solve this mixed delivery network problem efficiently which consists of two subproblems: distribution strategy selection and vehicle routing. Our new algorithm decides the selection of an appropriate distribution strategy and optimal routes using a heterogeneous fleet of vehicles at minimum cost.

Population size, mutation rate, and crossover rate parameters in the proposed algorithm have been determined by the literature review. The most optimal parameter values were determined by the Taguchi method, which is a statistical method for the correct combination of parameter values to make the study more reliable. The optimum parameter values found were used to generate a solution for all customer data samples.

Solutions for data samples involving up to 12 customers were obtained with both a linear programming model and the proposed algorithm. The performance of results was validated with statistical analysis. The paired sample $t$-test was performed to test whether the results obtained by the two methods gave similar results. The results of the paired sample $t$-test show that the two methods produce similar results. Therefore, it has been proved that our developed algorithm provides a good solution in reducing the supply chain distribution costs and computational time, especially for large-size problems.

Some future research points of this study would be as follows:

(i) The proposed heuristic algorithm in this paper can be used to solve similar network structure problems

(ii) Backhaul delivery strategy can be added to the models studied in this paper

(iii) When the number of vehicles is limited, the recommended routes, costs, and effects on the solution times can be examined (iv) Distribution strategies allowing split shipment can be studied

(v) Uncertain situations for demand and time can be taken into consideration

(vi) In case of need, opening or closing of additional distribution centers can be examined

\section{Data Availability}

The data set is added in the manuscript.

\section{Conflicts of Interest}

The authors declare that they have no conflicts of interest.

\section{Acknowledgments}

The authors gratefully thank DHL Supply Chain LLP Istanbul, Murat Colak, and Serkan Kabali in the problem definition and data preparation phases. Additionally, the authors would like to thank Dogus Teknoloji for their encouraging efforts in the completion of this study.

\section{References}

[1] S. Chopra and P. Meindl, Supply Chain Management, Pearson Education Inc, Hoboken, NJ, USA, 2007.

[2] T. Wall, "Consumer demand behind the wheel of roadway congestion: lean manufacturing lessons from a road raged operations executive. (the northwest lean networks," 2003, http://www.nwlean.net/article1003.htm.

[3] Y. Lin, Z. Bian, and S. Sun, "A two-phase heuristic algorithm for the common frequency routing problem with vehicle type choice in the milk run," Mathematical Problems in Engineering, vol. 2015, Article ID 404868, 2 pages, 2015.

[4] Z.-H. Hu, Y. Zhao, and T.-M. Choi, "Vehicle routing problem for fashion supply chains with cross-docking," Mathematical Problems in Engineering, vol. 2013, Article ID 362980, 10 pages, 2013.

[5] M. Fischetti, P. Toth, and D. Vigo, "A branch-and-bound algorithm for the capacitated vehicle routing problem on directed graphs," Operations Research, vol. 42, no. 5, pp. 846-859, 1994.

[6] G. Laporte and Y. Nobert, "Exact algorithms for the vehicle routing problem," Surveys in Combinatorial Optimization, vol. 31, pp. 147-184, 1987.

[7] J.-F. Cordeau, "A branch-and-cut algorithm for the dial-aride problem," Operations Research, vol. 54, no. 3, pp. 573586, 2006.

[8] A. Pessoa, E. Uchoa, and P. de Aragão, "The VRP: latest advances and new challenges," in Robust Branch-Cut-Price Algorithms for VRP, pp. 297-325, Springer, Berlin, Germany, 2008.

[9] R. Dondo, C. A. Méndez, and J. Cerdá, "The multi-echelon vehicle routing problem with cross docking in supply chain management," Computers \& Chemical Engineering, vol. 35, no. 12, pp. 3002-3024, 2011.

[10] A. Hasani-Goodarzi and R. Tavakkoli-Moghaddam, "Capacitated vehicle routing problem for multi-product cross- docking with split deliveries and pickups," ProcediaSocial and Behavioral Sciences, vol. 62, pp. 1360-1365, 2012. 
[11] F. A. Santos, G. R. Mateus, and A. S. da Cunha, "The pickup and delivery problem with cross-docking," Computers \& Operations Research, vol. 40, no. 4, pp. 1085-1093, 2013.

[12] D. Agustina, C. K. M. Lee, and R. Piplani, "Vehicle scheduling and routing at a cross docking center for food supply chains," International Journal of Production Economics, vol. 152, pp. 29-41, 2014.

[13] G. Clarke and J. W. Wright, "Scheduling of vehicles from a central depot to a number of delivery points," Operations Research, vol. 12, no. 4, pp. 568-581, 1964.

[14] A. Wren and A. Holliday, "Computer scheduling of vehicles from one or more depots to a number of delivery points," Journal of the Operational Research Society, vol. 23, no. 3, pp. 333-334, 1972.

[15] J. Xu, C.-L. Li, and C.-Y. Chan, "Mixed truck delivery systems with both hub-and-spoke and direct shipment," Transportation Research Part E: Logistics and Transportation Review, vol. 39, no. 4, pp. 325-339, 2003.

[16] R. Dondo and J. Cerdá, "A sweep-heuristic based formulation for the vehicle routing problem with cross-docking," Computers \& Chemical Engineering, vol. 48, pp. 293-311, 2013.

[17] H. Mei, Y. Jingshuai, M. Teng, L. Xiuli, and W. Ting, "The modeling of milk-run vehicle routing problem based on improved C-W algorithm that joined time window," Transportation Research Procedia, vol. 25, pp. 716-728, 2017.

[18] W. Cao and W. Yang, "A survey of vehicle routing problem," MATEC Web of Conferences, vol. 100, p. 01006, 2016.

[19] Y. H. Lee, J. W. Jung, and K. M. Lee, "Vehicle routing scheduling for cross-docking in the supply chain," Computers \& Industrial Engineering, vol. 51, no. 2, pp. 247-256, 2006.

[20] M. Wen, J. Larsen, J. Clausen, J.-F. Cordeau, and G. Laporte, "Vehicle routing with cross-docking," Journal of the Operational Research Society, vol. 60, no. 12, pp. 1708-1718, 2009.

[21] R. Musa, J.-P. Arnaout, and H. Jung, "Ant colony optimization algorithm to solve for the transportation problem of cross-docking network," Computers \& Industrial Engineering, vol. 59, no. 1, pp. 85-92, 2010.

[22] S. Moghadam, S. Fatemi Ghomi, and B. Karimi, "Vehicle routing scheduling problem with cross docking and split deliveries," Computers \& Chemical Engineering, vol. 69, no. 3, pp. 98-107, 2014.

[23] S. M. Mousavi and R. Tavakkoli-Moghaddam, "A hybrid simulated annealing algorithm for location and routing scheduling problems with cross-docking in the supply chain," Journal of Manufacturing Systems, vol. 32, no. 2, pp. 335-347, 2013.

[24] S. D. Hosseini, M. A. Shirazi, and B. Karimi, "Cross-docking and milk run logistics in a consolidation network: a hybrid of harmony search and simulated annealing approach," Journal of Manufacturing Systems, vol. 33, no. 4, pp. 567-577, 2014.

[25] S. J. Sadjadi, M. Jafari, and T. Amini, "A new mathematical modeling and a genetic algorithm search for milk run problem (an auto industry supply chain case study)," The International Journal of Advanced Manufacturing Technology, vol. 44, no. 1-2, pp. 194-200, 2009.

[26] A. Baniamerian, M. Bashiri, and F. Zabihi, "Two phase genetic algorithm for vehicle routing and scheduling problem with cross-docking and time windows considering customer satisfaction," Journal of Industrial Engineering International, vol. 14, no. 1, pp. 15-30, 2017.

[27] A. Baniamerian, M. Bashiri, and R. Tavakkoli-Moghaddam, "Modified variable neighborhood search and genetic algorithm for profitable heterogeneous vehicle routing problem with crossdocking," Applied Soft Computing, vol. 75, pp. 441-460, 2019.
[28] H. Charkhgard and A. A. Yahya Tabar, "Transportation problem of cross-docking network with three-dimensional trucks," African Journal of Business Management, vol. 5, no. 22, pp. 9297-9303, 2011.

[29] H. Li, M. Liang, and T. He, "Optimizing the composition of a resource service chain with interorganizational collaboration," IEEE Transactions on Industrial Informatics, vol. 13, no. 3, pp. 1152-1161, 2017.

[30] D. J. Garcia and F. You, "Supply chain design and optimization: Challenges and opportunities," Computers \& Chemical Engineering, vol. 81, pp. 153-170, 2015.

[31] R. Zhao, Y. Liu, N. Zhang, and T. Huang, "An optimization model for green supply chain management by using a big data analytic approach," Journal of Cleaner Production, vol. 142, pp. 1085-1097, 2017.

[32] R. Wang, Q. Sun, D. Ma, and Z. Liu, "The small-signal stability analysis of the droop-controlled converter in electromagnetic timescale," IEEE Transactions on Sustainable Energy, vol. 10, no. 3, pp. 1459-1469, 2019.

[33] H. Zhang, Y. Li, D. W. Gao, and J. Zhou, "Distributed optimal energy management for energy internet," IEEE Transactions on Industrial Informatics, vol. 13, no. 6, pp. 3081-3097, 2017.

[34] Y. Li, H. Zhang, X. Liang, and B. Huang, "Event-triggeredbased distributed cooperative energy management for multienergy systems," IEEE Transactions on Industrial Informatics, vol. 15, no. 4, pp. 2008-2022, 2019.

[35] Y. Li, H. Zhang, B. Huang, and J. Han, "A distributed Newton-Raphson-based coordination algorithm for multiagent optimization with discrete-time communication," Neural Computing and Applications, pp. 1-15, 2018.

[36] U. M. Apte and S. Viswanathan, "Effective cross docking for improving distribution efficiencies," International Journal of Logistics Research and Applications: A Leading Journal of Supply Chain Management, vol. 3, no. 3, pp. 291-302, 2016.

[37] V. F. Yu, P. Jewpanya, and A. A. N. P. Redi, "Open vehicle routing problem with cross-docking," Computers \& Industrial Engineering, vol. 94, pp. 6-17, 2016.

[38] J.-F. Cordeau, M. Gendreau, A. Hertz, G. Laporte, and J. Sormany, "New heuristics for the vehicle routing problem," in Logistics Systems: Design and Optimization, A. A. Langevi, Ed., pp. 279-297, Springer, New York, NY, USA, 2005.

[39] M. Gendreau, G. Laporte, and J.-Y. Potvin, "Metaheuristics for the VRP," in The Vehicle Routing Problem, P. Toth and D. Vigo, Eds., pp. 129-154, SIAM Monographs on Discrete Mathematics and Applications, Philadelphia, 2002.

[40] N. S. Kumar and R. Panneerselvam, "A survey on the vehicle routing problem and its variants," Intelligent Information Management, vol. 4, no. 3, pp. 66-74, 2012.

[41] G. Laporte, "The vehicle routing problem: an overview of exact and approximate algorithms," European Journal of Operational Research, vol. 59, no. 3, pp. 345-358, 1992.

[42] G. Laporte, "Fifty years of vehicle routing," Transportation Science, vol. 43, no. 4, pp. 408-416, 2009.

[43] C.-J. Liao, Y. Lin, and S. C. Shih, "Vehicle routing with crossdocking in the supply chain," Expert Systems with Applications, vol. 37, no. 10, pp. 6868-6873, 2010.

[44] S. Mousavi, B. Vahdani, R. Tavakkoli-Moghaddam, and H. Hashemi, "Location of cross-docking centers and vehicle routing scheduling under uncertainty: a fuzzy possibilisticstochastic programming model," Applied Mathematical Modelling, vol. 38, no. 7-8, pp. 2249-2264, 2014.

[45] J. Wang, A. K. Ranganathan Jagannathan, X. Zuo, and C. C. Murray, "Two-layer simulated annealing and tabu search heuristics for a vehicle routing problem with cross 
docks and split deliveries," Computers \& Industrial Engineering, vol. 112, pp. 84-98, 2017.

[46] A. Ahkamiraad and Y. Wang, "Capacitated and multiple cross-docked vehicle routing problem with pickup, delivery, and time windows," Computers \& Industrial Engineering, vol. 119, pp. 76-84, 2018.

[47] Z. You and Y. Jiao, "Development and application of milk-run distribution systems in the express industry based on saving algorithm," Mathematical Problems in Engineering, vol. 2014, Article ID 536459, 6 pages, 2014.

[48] O. Berman and Q. Wang, "Inbound logistic planning: minimizing transportation and inventory cost," Transportation Science, vol. 40, no. 3, pp. 287-299, 2006.

[49] J. Branke, D. Haußler, and C. Schmidt, "Transport channel selection," Operations Research Proceedings, pp. 349-354, 2006.

[50] M. Cóccola, C. A. Méndez, and R. G. Dondo, "A branch-andprice approach to evaluate the role of cross-docking operations in consolidated supply chains," Computers \& Chemical Engineering, vol. 80, pp. 15-29, 2015.

[51] A. Goodarzi and S. Zegordi, "A location-routing problem for cross-docking networks: a biogeography-based optimization algorithm," Computers \& Industrial Engineering, vol. 102, pp. 132-146, 2016.

[52] A. Meyer and B. Amberg, "Transport concept selection considering supplier milk runs - an integrated model and a case study from the automotive industry," Transportation Research Part E: Logistics and Transportation Review, vol. 113, pp. 147-169, 2018.

[53] M. Held and R. M. Karp, "The traveling-salesman problem and minimum spanning trees," Operations Research, vol. 18, no. 6, pp. 1138-1162, 1970.

[54] M. D. Syslo, Discrete Optimization Algorithms with Pascal Programs, Prentice-Hall, Englewood Cliffs, NJ, USA, 1983.

[55] M. Mokhtarinejad, A. Ahmadi, B. Karimi, and S. H. A. Rahmati, "A novel learning based approach for a new integrated location-routing and scheduling problem within cross-docking considering direct shipment," Applied Soft Computing, vol. 34, pp. 274-285, 2015.

[56] K. DeJong, An analysis of the behaviour of a class of genetic adaptive systems, Ph.D. thesis, University of Michigan, Arbor, MI, USA, 1975.

[57] J. Grefenstette, "Optimization of control parameters for genetic algorithms," IEEE Transactions on Systems, Man, and Cybernetics, vol. 16, no. 1, pp. 122-128, 1986.

[58] C. Iris and S. S. Asan, "A review of genetic algorithm applications in supply chain network design," in Atlantis Computational Intelligence Systems, C. Kahraman, Ed., vol. 6, pp. 203-230, Atlantis Press, Springer, Berlin, Germany, 2012.

[59] D. E. Goldenberg, Genetic Algorithms in Search Optimization and Machine Learning, Addion Wesley Longman, Boston, MA, USA, 1989.

[60] L. Lin, M. Gen, and X. Wang, "Integrated multistage logistics network design by using hybrid evolutionary algorithm," Computers \& Industrial Engineering, vol. 56, no. 3, pp. 854873, 2009.

[61] L. Lin, M. Gen, and X. Wang, "A hybrid genetic algorithm for logistics network design with flexible multistage model," International Journal of the Information Systems for Logistics and Management, vol. 3, no. 1, pp. 1-12, 2007.

[62] G. Taguchi and S. Konishi, Taguchi Methods, Orthogonal Arrays and Linear Graphs, Tools for Quality American Supplier, American Supplier Institute, Nasr City, Egypt, 1987. 